\title{
The relationship between technical support and pedagogical guidance provided to faculty and student satisfaction in online courses
}

Philip R. Ice

West Virginia University

Follow this and additional works at: https://researchrepository.wvu.edu/etd

\section{Recommended Citation}

Ice, Philip R., "The relationship between technical support and pedagogical guidance provided to faculty and student satisfaction in online courses" (2006). Graduate Theses, Dissertations, and Problem Reports. 3467.

https://researchrepository.wvu.edu/etd/3467

This Dissertation is protected by copyright and/or related rights. It has been brought to you by the The Research Repository @ WVU with permission from the rights-holder(s). You are free to use this Dissertation in any way that is permitted by the copyright and related rights legislation that applies to your use. For other uses you must obtain permission from the rights-holder(s) directly, unless additional rights are indicated by a Creative Commons license in the record and/ or on the work itself. This Dissertation has been accepted for inclusion in WVU Graduate Theses, Dissertations, and Problem Reports collection by an authorized administrator of The Research Repository @ WVU.

For more information, please contact researchrepository@mail.wvu.edu. 


\title{
THE RELATIONSHIP BETWEEN TECHNICAL SUPPORT AND PEDAGOGICAL GUIDANCE PROVIDED TO FACULTY AND STUDENT SATISFACTION IN ONLINE COURSES
}

\author{
Philip R. Ice \\ Dissertation submitted to the \\ College of Human Resources and Education \\ at West Virginia University \\ in partial fulfillment of the requirements for the \\ degree of \\ Doctor of Education \\ in \\ Curriculum and Instruction \\ Randy Wiesenmayer, Ph.D., Chair \\ John Oughton, Ed.D \\ Perry Phillips, Ed.D. \\ Jim Rye, Ph.D \\ Allison Swan Dagen, Ph.D. \\ John Wells, Ph.D \\ Department of Curriculum \& Instruction / Literacy Studies
}

Morgantown, West Virginia 2006

Keywords: Online Courses, Faculty Satisfaction, Student Satisfaction, Technological Support, Pedagogical Guidance, Training

Copyright 2006 Philip R. Ice 


\section{ABSTRACT \\ The Relationship Between Technical Support and Pedagogical Guidance Provided to Faculty and Student Satisfaction in Online Courses}

Philip R. Ice

This study examined the relationship between levels of technical support and pedagogical guidance provided to faculty and student satisfaction in online courses. Online learning is a rapidly evolving area of education, yet compared to traditional face-to-face learning very little is known about pedagogical techniques and best practices. This study explores the relationships between two factors that have been demonstrated to influence faculty satisfaction, technical support and pedagogical guidance (the predictor variables), and student satisfaction (the criterion variable) in online courses. The study uses quantitative methods to determine if varying levels of predictor variable input are related to changes in the criterion variable.

In this study, 15 faculty members received varying levels of technical support and pedagogical guidance over a two year period. Student satisfaction surveys were administered to a total of 519 students in their online courses offered by these instructors. Data for two well recognized measures of student satisfaction, instructional design / organization and facilitation of discourse, were extracted from the completed surveys. Multiple regression analysis was used to determine the nature of the relationships that existed between these two criterion variables (instructional design / organization and facilitation of discourse) and two predictor variables, hours of technical support and pedagogical guidance.

Regression analysis revealed that only $2.9 \%$ of the variance in student satisfaction with instructional design / organization can be accounted for by quantitative measures of technical support and pedagogical guidance provided to faculty. With respect to facilitation of discourse, only $1.8 \%$ of the variance in student satisfaction can be accounted for by quantitative measures of technical support and pedagogical guidance provided to faculty. These findings indicate that faculty development programs that are based strictly on hours of contact are not likely to be effective in producing high levels of student satisfaction in online courses. An in-depth qualitative approach, such as multiple program analyses, is suggested to unearth the relationships that exist between factors that promote faculty satisfaction and those that promote student satisfaction in online courses. 


\section{ACKNOWLEDGEMENTS}

First, and foremost, I want to thank Faye Phillips, my constant companion, inspiration and source of strength. Without her, this work would not have been possible. I also want to express my gratitude to my committee members who have provided me with feedback, encouragement and a tremendous amount of support. I would especially like to thank Dr. Randy Wiesenmayer, my chair, and Dr. Perry Phillips. Both have been exceptional mentors and friends.

I would like to thank Dr. John Wells for being choosing to support me from a distance and take my endless phone calls filled with tedious questions about minute details. I would like to thank Dr. Jim Rye for not only being on my committee but for giving me the opportunity to participate in the faculty training program that's at the heart of this study. I would like to thank Dr. John Oughton for helping me navigate my way through our learning management system and for asking me to look at my research from different perspectives. I would like to thank Dr. Allison Swan Dagen for helping me out when I was very much in need of support.

I wish to thank all of the faculty from the College of Human Resources and Education who allowed me to collect data from their courses. Without the broad-based support I received in this undertaking would not have been possible. I hope the data proves to be as valuable to the participants as it was to me.

Finally, I wish to thank several individuals who helped me through providing expert insight into this topic: Dr. Karen Swan, Dr. Tana Bishop, Dr. Peter Shea, Dr. Boria Sax and Dr. Frank McCluskey. Their understanding of the online world was, to me, invaluable. 


\section{TABLE OF CONTENTS}

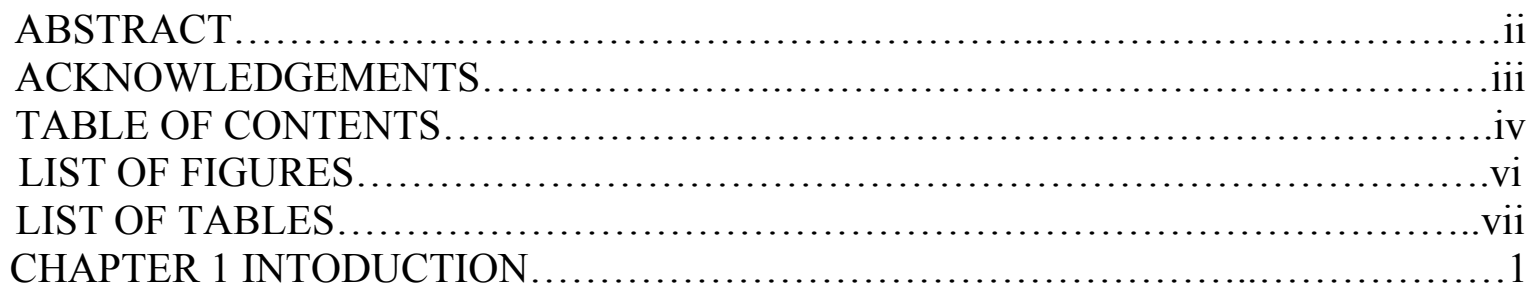

Problem Statement........................................................... 3

Purpose Statement............................................................6

The Online Course Initiative at West Virginia University's College

of Human Resources \& Education and Personal Involvement..................8

Rationale for the Study................................................... 10

Research Questions....................................................... 12

CHAPTER 2 LITERATURE REVIEW ........................................ 13

Faculty Satisfaction...................................................... 14

The Transformation from Traditional Teaching to ALN.........................14

The University of Central Florida Experience ................................. 17

The State University of New York Experience.................................18

The Virginia Tech Experience........................................... 19

The Colorado State University Experience.................................20

The Brandon University Experience.....................................21

Cross Case Analysis.....................................................22

Student Satisfaction...................................................... 25

Connecting Faculty and Student Satisfaction in the OILM......................27

Faculty Support and Student Satisfaction at West Virginia

University's College of Human Resources and Education........................29

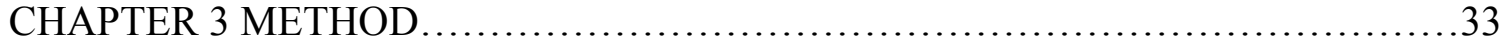

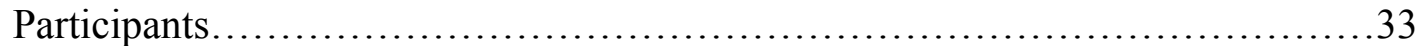

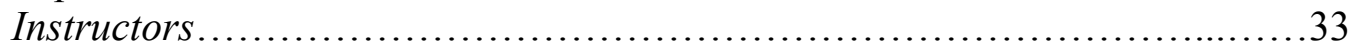

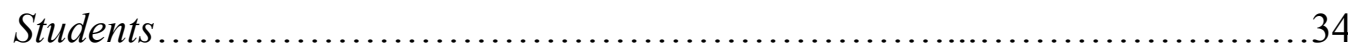

Research Questions................................................... 35

Research Design....................................................... 35

Instruments........................................................... 37

Methodology for Ascertaining Hours Technical Support and Pedagogical

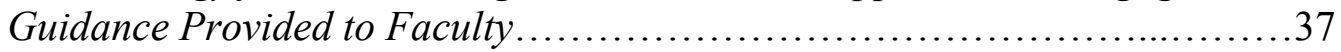

Student Satisfaction Survey............................................. 37

Instructional Design and Organization Subscale...........................38

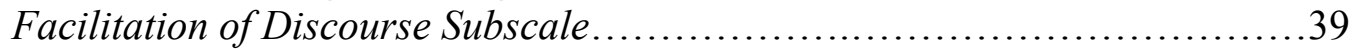

Validity of Subscales.................................................40

Reliability of Subscales...................................................41

Data Collection........................................................... 42

Procedure.............................................................. 43

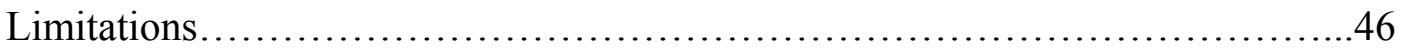


Sample Size............................................................ 46

Homogeneity of Participants ............................................47

Previous Training in Online Course Development and Teaching................47

Skills Acquired Through Informal Processes..................................48

Subscale Item Discrepancies.............................................48

Measurement of Technical Support and Pedagogical Guidance...............49

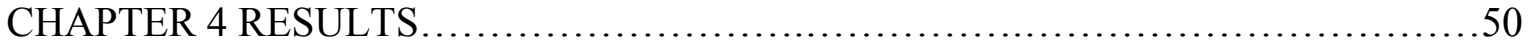

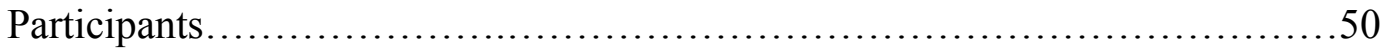

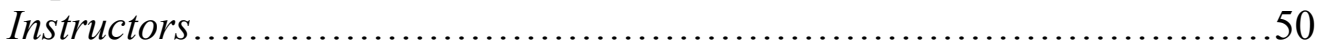

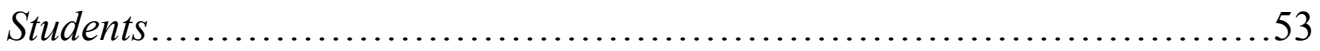

Quantitative Analysis of Data...........................................53

Regression Analyses for Instructional Design and Organization...............53

Tests of Linearity and Homogeneity ......................................55

Tests of Multicolinearity.............................................5

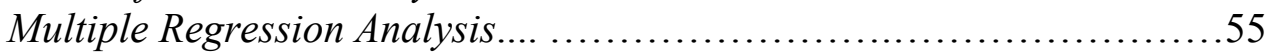

Regression Analyses for Facilitation of Discourse ..............................55

Tests of Linearity and Homogeneity ....................................56

Tests of Multicolinearity ...........................................5

Multiple Regression Analysis...............................................................57

Summary of Results.................................................5 58

CHAPTER 5 CONCLUSIONS, RECOMMENDATIONS AND IMPLICATIONS.....59

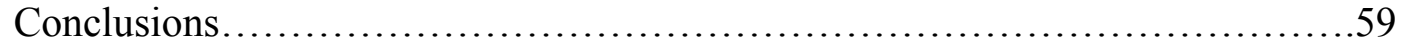

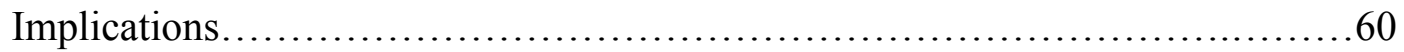

Implications for Practice ............................................61

Implications for Theory ............................................62

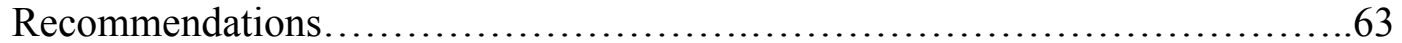

Recommendations for Practice ........................................66

Recommendations for Further Research ...............................65

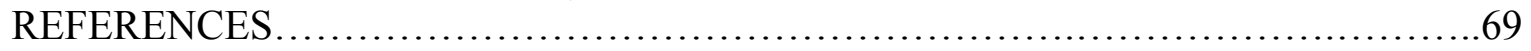

Appendix A Student Satisfaction Survey ........................................... 78

Appendix B Instructional Organization and Design Subscale............................101

Appendix C Facilitation of Discourse Subscale..........................................104 


\section{LIST OF FIGURES}

Figure 1. Moderator and output variables in the online interaction learning model.......3 Figure 2. Bivariate scatterplot of the relationship between pedagogical guidance and instructional design / organization.......................................... 44 Figure 3. Means plot of the relationship between pedagogical guidance and instructional design / facilitation.................................................... 45 


\section{LIST OF TABLES}

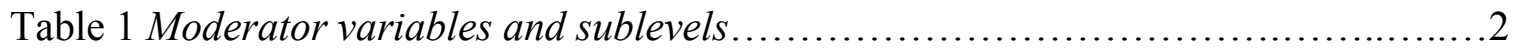

Table 2 Employment Status and ALN Teaching Experience of Faculty .....................34

Table 3 Cumulative Hours of Technical Support and Pedagogical Guidance Provided to Faculty Who Taught Online Courses During the Spring Semester of 2005 ....51

Table 4 Cumulative Hours of Technical Support and Pedagogical Guidance Provided to Faculty Who Taught Online Courses During the Summer Semester of 2005...51

Table 5 Cumulative Hours of Technical Support and Pedagogical Guidance Provided to Faculty Who Taught Online Courses During the Fall Semester of 2005.........52

Table 6 Cumulative Hours of Technical Support and Pedagogical Guidance Provided to Faculty Who Taught Online Courses During the Spring Semester of 2006......52

Table 7 Levene's t-tests on Two Predictors and One Co-Predictors by Instructional Design / Organization..........................................................54

Table 8 Multiple Regression on Instructional Design / Organization Using Two Predictors and One Co-Predictor. .55

Table 9 Levene's t-tests on Two Predictors and One Co-Predictors by Facilitation of Discourse ...................................................................56

Table 10 Multiple Regression on Facilitation of Discourse Using Two Predictors and One Co-Predictor. 


\section{CHAPTER 1 \\ INTRODUCTION}

Over 2.3 million students were registered in online courses in the Fall semester of 2004 (Allen \& Seaman, 2005). This figure represented an annual growth rate of $18.2 \%$ over the previous year and was 10 times higher than the growth rate for traditional courses during the same period. With respect to future trends, $56 \%$ of administrators at postsecondary institutions believe an online presence is a critical part of long-term strategy and double-digit growth rates are predicted throughout the next decade. These numbers clearly indicate that online learning will continue to play an increasingly larger role in higher education; however, what is less certain is what constitutes best practice in this environment. Compared to traditional face-to-face learning very little is known about pedagogical techniques and best practices in Asynchronous Learning Networks (ALN) (Hawkins, 2005). This study explores the relationship between quantifiable measures of technical support and pedagogical guidance provided to ALN faculty (the predictor variables) and student satisfaction with instructional design / organization and facilitation of discourse (the criterion variables), in an effort to gain an initial understanding of what might constitute best practice from a developmental perspective.

Current ALN models are based on a moderator-mediator-output framework of learning known as the Online Interaction Learning Model (OILM) (Benbunan-Fich, Hiltz \& Harasim, 2005). Within the OILM, there are four moderator variables. Each of these moderator variables have a varying numbers of sublevels that interact in the learning process and allow for the construction of knowledge. 
Table 1

Moderator Variables and Sublevels

\begin{tabular}{|l|l|l|l|}
\hline Technology & Course & $\begin{array}{l}\text { Instructor } \\
\text { Characteristics }\end{array}$ & $\begin{array}{l}\text { Student } \\
\text { Characteristics }\end{array}$ \\
\hline Mode (Media Mix) & Course Type & Skills & Motivation \\
\hline Time Dispersion & Class Size & Effort & Ability \\
\hline $\begin{array}{l}\text { Geographical } \\
\text { Dispersion }\end{array}$ & Type of Subject & Pedagogical Model & Attributes \\
\hline $\begin{array}{l}\text { Software } \\
\text { Functionality }\end{array}$ & $\begin{array}{l}\text { Institutional } \\
\text { Context }\end{array}$ & & Learning Styles \\
\hline Software Interface & & & \\
\hline Reliability & & & \\
\hline Media Bandwidth & & & \\
\hline
\end{tabular}

The five output variables in the OILM are referred to in the ALN research community as the Five Pillars of Quality Effectiveness (Moore, 2002). Initially proposed by Mayadas (Mayadas, Bourne \& Moore, 2002), the Five Pillars consist of: learning effectiveness, cost effectiveness, access, student satisfaction and faculty satisfaction.

Each of these output variables then acts to modify the moderator variables in a feedback loop leading to continual improvement of the learning process. For example, if data reveal that a change in course design has resulted in significant positive or negative effects at the output level, changes are made to corresponding input variables in the design and delivery of future courses.

As each of the moderator variables is subject to numerous interactions and filtering at the mediator level, it is theorized that actions influencing any given moderator variable should create a measurable impact on any of the output variables; i.e., the five pillars of quality effectiveness (Benbunan-Fich, et al., 2005). Diagram 1.1 illustrates the OILM framework: 


\section{Moderator Variables}

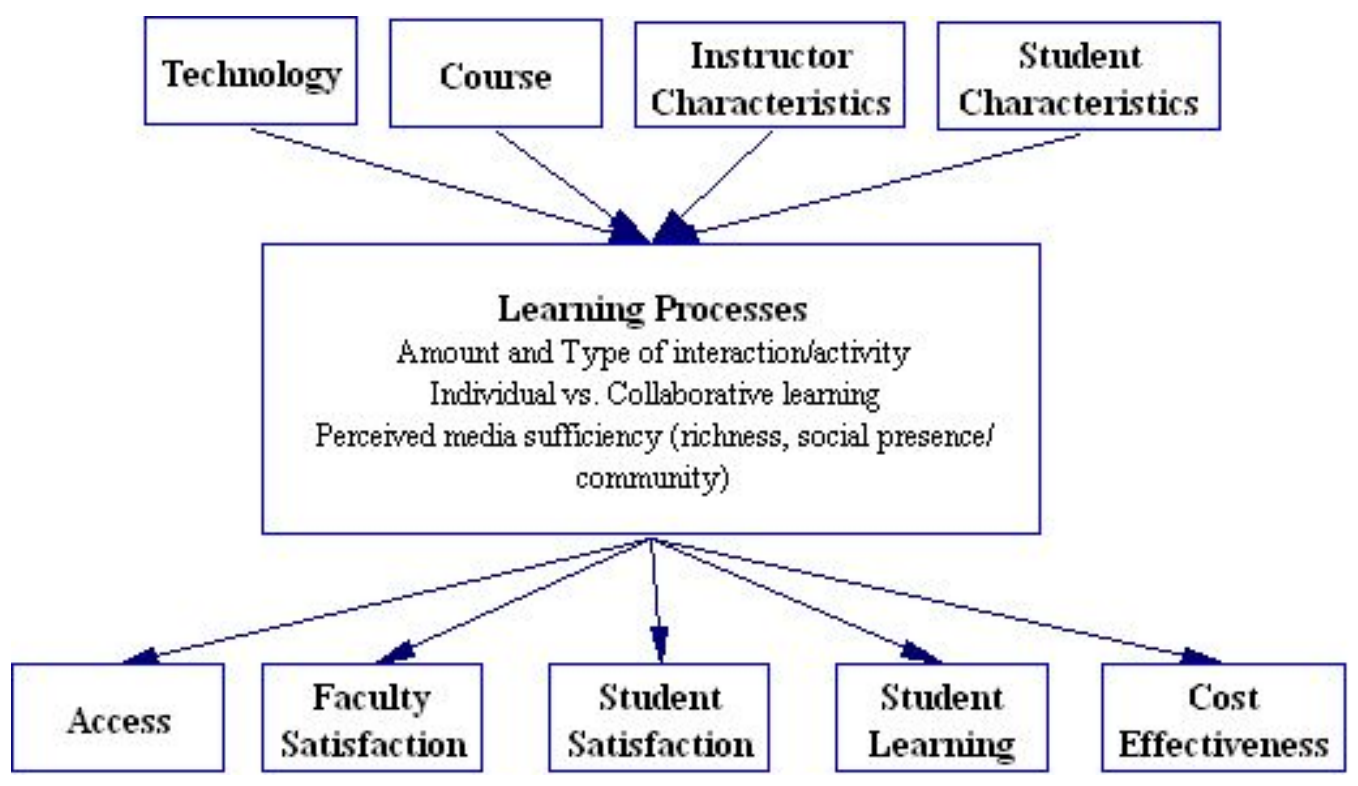

\section{Output Variables}

Figure 1. Moderator and output variables in the online interaction learning model

Some of the interactions that occur in the OILM that have been explored demonstrate correlations between motivation and learning (Hiltz \& Wellman, 1997;

Allen \& Thompson, 1995). However, this represents only an extremely small sampling of the possible OILM connections and calls for considerably more research related to each of the variables and the interactions between sets of variables that exist in the field (Benbunan-Fich et al., 2005). One such call for research made by Bishop and SchWeber (2004) focuses on the need to develop a better understanding of the relationship between faculty and student satisfaction which is the purpose of this study.

\section{Problem Statement}

Understanding the relationship between faculty satisfaction and the support they receive is a rather straightforward proposition and is fairly well defined in comprehensive 
program evaluations such as the State University of New York learning networks (SLN) study conducted by Fredrickson, Pickett, Shea, Pelz and Swan (2000). In this study, key findings related to faculty satisfaction included a need for: individual instructional design support and technical support, collecting and sharing best practices and resources that support applications in a variety of media.

Other case study compilations of best developmental practices (Cook \& GrantDavie, 2005; Brown, 2003; Epper \& Bates, 2001) point to faculty having continued access to technical support and pedagogical guidance mechanisms as being key to program success. As a contra-indicator, Ferrazzi’s (2003) case study of the failed experience at Brandon University is useful in affirming the importance of adequate support and guidance structures. The inability of faculty to access meaningful levels of support and guidance at Brandon led to widespread dissatisfaction and caused the initiative to stagnate.

In the literature, the relationship between levels of faculty support and student satisfaction is less clear, though some indicators are present. From the student's perspective the most common concerns about participating in an online course are:

1. Will the course be of the same quality that I could expect in a traditional classroom?

2. Do I have the technological skills necessary for taking an online course?

3. Are technical support services available?

4. What type of access will I have to the instructor?

5. How will the workload compare to a traditional course?

(Hiltz \& Shea, 2005; Maeroff, 2003; Reath, 2001) 
The first of these issues, comparative quality is clearly related to how well the instructor is able to adapt pedagogical principles to the online environment (Cook \& Grant-Davie, 2005). Though pedagogy remains an area in which much research needs to be conducted (Hawkins, 2005), the overwhelming consensus reached in the literature is that a sound pedagogical basis is necessary for the course to be successful and therefore be perceived as satisfactory by students ( Hiltz \& Shea, 2005).

With respect to technical support services, two findings are important to note. First, Monolescu, Schifter and Greenwood (2003) found that the ability of students to easily login, view (web based content), work with and manipulate learning materials was key to success. For many instructors, structuring learning materials in such a way that they are accessible in this fashion calls for technical support in the development process (Royal, 2005). Second, Lynch (2001) found that faculty had less time interacting with content-related issues when they spent excessive amounts of time troubleshooting technical problems experienced by students. For students this resulted in a perceived lack of quality engagement.

Finally, from the student's perspective it is desirable that the workload not be substantially greater in an online course than it would be in the traditional setting. However, as Bender (2003) points out, faculty often tend to make online assignments more difficult to compensate for what they perceive to be shortcomings of ALN. Here it is obvious that if faculty understand that online learning is just as or more effective than traditional learning (Fjermestad, Hiltz \& Zhang, 2005), then proper pedagogical guidance would allow for the development of activities that would likewise be comparable to traditional counterparts in terms of workload and effort required. 
Shea, Swan, Li and Pickett (2005) found that instructional design/organization and facilitation of discourse account for 70 percent of the variance in ALN student satisfaction. Earlier theoretical constructs upon which this research was based defined these two elements as being critical to establishing teaching presence in ALN. Specifically, instructional design and organization consists of the following indicators:

- setting curriculum

- designing methods

- establishing time parameters

- utilizing the medium effectively

- establishing netiquette

(Anderson, Rourke, Garrison \& Archer, 2001)

Indicators that define effective facilitation of discourse are:

- identifying areas of agreement and disagreement

- seeking to reach consensus and understanding

- encouraging, acknowledging, and reinforcing student contributions

- setting the climate for learning

- drawing in participants and prompting discussion

- assessing the efficacy of the process

(Anderson, Rourke, Garrison \& Archer, 2001)

This study uses multiple regression analyses to answer the following research questions: 1) What is the relationship between technical support provided to faculty and student satisfaction? 2) What is the relationship between pedagogical support provided to faculty and student satisfaction in ALN?

\section{Purpose Statement}

From a theoretical perspective, the cyclical feedback structure of the OILM itself suggests that a relationship should exist between: 1) Technical support provided to 
faculty and student satisfaction, and 2) Pedagogical guidance provided to faculty and student satisfaction. Harasim (1990) points out, in moderator-mediator-output models of conceptual change, that contextual factors interact with each other to create change at all levels in a continuous feedback loop. As this is the basis for the OILM, such dynamic changes to the moderator variables should produce change at the output level (BenbunanFich et al., 2005). Therefore, changes to technical support and pedagogical guidance at the instructor-characteristics moderator level should impact both faculty and student satisfaction.

With respect to best practice, Hiltz and Shea (2005) indicate that it is necessary to assess the impact of faculty support on student learning and satisfaction to understand how to best facilitate success. Though they cite several studies (Shea, Swan, Fredrickson \& Pickett, 2002; Fredricksen et al., 2000; Hartman, Dziuban \& Moskal, 2000) that indicate strong correlations between faculty development/support and effective course design/management, Hiltz and Shea believe that the research is incomplete. Specifically they indicate a need for a systematic analysis of the relationship between faculty development/support and factors that promote student success.

An earlier call for research, by Bishop and SchWeber (2004), clarifies the need for a systematic investigation of the correlation between these factors by arguing that early ALN research utilized a silo approach in which moderator and mediator factors were studied in a linear, isolated fashion. For example, variables associated with student characteristics were correlated with student satisfaction and variables associated with faculty characteristics were correlated with faculty satisfaction. Bishop and SchWeber believe that the body of research is now adequate to begin applying a systems thinking 
approach to the factors that support the OILM. Specifically they argue that the interrelationship between variables that promote faculty satisfaction and student satisfaction should be examined concurrently to produce a better understanding of integrated factors that reflects academic reality, which single factor approaches fail to address.

The Online Course Initiative at West Virginia University's College of Human Resources \& Education and Personal Involvement

As part of West Virginia University's (WVU) mission to expand learning access to an increasingly diverse student body, the College of Human Resources and Education (HR\&E) administration has encouraged faculty to offer a number of courses either fully online or in hybrid online/face-to-face formats. In this process, HR\&E administration has struggled with finding the best means by which to support faculty. In a process similar to what is occurring at many other institutions, the support initiative is constantly evolving in an effort to provide faculty with the needed resources while optimizing student satisfaction and learning.

Though not formally recognized as such, elements of the HR\&E support initiative bear a close resemblance to those utilized by other institutions in that it attempts to promote learning effectiveness, cost effectiveness, access, student satisfaction and faculty satisfaction; i.e., the five pillars of quality effectiveness. Since 2002, faculty have been offered access to an intensive 40-hour program, known as the Faculty Academy, that emphasizes the analysis of the pedagogical basis for exemplar courses. Faculty Academy workshops provide hands-on experiences that are intended to develop skills related to webpage design and use of the course management system, currently WebCT Vista. 
Follow-up support after the end of the Faculty Academy is less formalized than the core program and varies from department to department within the college.

In some cases, more experienced faculty mentor their peers who are developing online courses on an as-needed-basis. Utilizing Graduate Assistants (GA's) in the HR\&E's computer lab is another resource available to faculty who need help with the technical aspects of webpage design and importing resources into the Vista platform. The only department which offers formalized, ongoing support to faculty is Educational Theory and Practice (ETP).

In the Spring of 2004, I became involved, as a GA, in providing support to ETP faculty who required technical support and pedagogical guidance in the development and support of online courses. Since that time I have helped develop and support 22 online courses for 11 faculty members. In addition, I assisted in planning and facilitating the 2005 Faculty Academy.

By serving in this support role, I have had significant exposure to moderator variables related to instructor characteristics, especially technical support and pedagogical guidance. With respect to the output variables, I have been involved in administering student satisfaction surveys and have conducted a qualitative study faculty satisfaction.

This study revealed that ongoing technical support was the most important factor influencing satisfaction in ALN development and delivery (Ice \& Phillips, 2006). Access to pedagogical guidance and instructional designers with a background in ALN was considered the second most important factor. Faculty often felt overwhelmed by the evolution of delivery options and in a majority cases $(n=8$ of 11$)$, they indicated that 
they would be unlikely to continue teaching courses via ALN if they did not have access to technical support and pedagogical guidance at current or increased levels.

Through my involvement with the collection of student satisfaction surveys, I began to develop an interest in the relationship between faculty and student satisfaction. In the qualitative response sections of the student satisfaction survey, as well as in informal feedback, a substantial number of students commented that they were very satisfied with their experience in a given course because it was user friendly, well structured, logically ordered, was similar in approach to what they would have expected in a traditional course, or other considerations that were thematically similar.

Upon reflection, I realized that most if not all of these elements resulted from the support that had been provided to faculty in the design and development of their courses. These were also the types of support that had been identified as primary factors influencing HR\&E faculty satisfaction (Ice \& Phillips, 2006). This feedback is the basis for choosing the relationship between faculty satisfaction and student satisfaction as the areas of focus of this study.

\section{Rationale for the Study}

Despite ALN research being in its infancy and a lack of detail in some of the literature, contemporary evaluations of best practice provide a foundation for establishing adequate levels of technical support and pedagogical guidance as being integral to faculty satisfaction. The institutional perspectives presented in the review of literature, as well as other editorial type overviews (Brown, 2003), depict successful ALN initiatives as being ones in which organized and effective design teams assist faculty in continual course improvement. In this process, overall faculty satisfaction is enhanced (Fredrickson et al. 
2000; Hartman et al. 2000) and program continuation is far more likely than in instances where support levels are low (Ferrazzi, 2003).

Theoretically the OILM suggests that a correlation should exist between any given set of moderator and output variables, as the framework is based on dynamic interactions in the mediator process and continuous feedback loops (Benbunan-Fich et al. 2005). From a teaching presence perspective, work by Shea and colleagues (Shea et al. 2005) demonstrates that indeed student satisfaction is largely a function of two factors: instructional design/organization and facilitation of discourse, that previous studies have shown are dependent upon high levels of technical support and pedagogical guidance in successful initiatives. Therefore, determining if it is possible to correlate support input levels with student satisfaction would be significant in understanding how to provide optimal support structures for emerging and ongoing ALN programs at the institutional level.

In the experience at WVU's College of HR\&E, the study of faculty satisfaction illustrates the importance of technical support and pedagogical guidance with respect to faculty satisfaction in the development and implementation of ALN (Ice \& Phillips, 2006). Data gathered in the 2005 study also suggest that the correlation between these factors and student satisfaction are likely to exist.

This study will examine the impact of technical support and pedagogical guidance on student satisfaction. If a significant correlation is found to exist it would serve to reinforce the theoretical basis of the OILM, contribute to the literature and support the ALN development initiative at the study's host institution, WVU. Though the rationale lacks multiple support points that are present in many studies of this nature, the newness 
of the research area and support from leading ALN researchers, for this type of inquiry, should be considered offsetting factors.

\section{Research Questions}

This study used multiple regression analysis to answer the following research questions:

1. What is the relationship between technical support and pedagogical guidance provided to faculty (the predictor variables) and student satisfaction with instructional design / organization (the criterion variable) in ALN?

2. What is the relationship between technical support and pedagogical guidance provided to faculty (the predictor variables) and student satisfaction with facilitation of discourse (the criterion variable) in ALN? 


\section{CHAPTER 2}

\section{LITERATURE REVIEW}

The Online Interaction Learning Model and the Five Pillars of Quality

Several frameworks have been proposed to define the theoretical basis for learning in ALN. The most widely accepted, the OILM, is derivative of the information systems (IS) moderator-mediator-output model. Alavi and Leidner (2001) examined several ALN and coded participant actions in terms of intent and results. The architecture that emerged was found to be representative of the processes that occur in already well defined moderator (input) - mediator (process) - output models.

This model was later modified by Benbunan-Fich, et al. (2005) to include contingency theory. This addition, while supporting the moderator-mediator-output construct, differs from the linear IS approach in that it accounts for continuous feedback loops that are present in ALN. In an earlier work, Hiltz (1988) conducted an analysis of computer-mediated communication and found that complex socially and technology influenced interactions occur at all levels of the process. Therefore the currently accepted OILM is one in which minimal levels of input are necessary for subsequent processes to occur in the moderator-mediator-output sequence. In addition, feedback from each of these levels will impact subsequent actions within and between the others.

Within the OILM framework Benbunan-Fich, et al., (2005) identify the following moderator variables: technology, course, instructor characteristics and student characteristics. As per contingency theory, interactions occur between each of these in the learning process or mediator level. The output variables are then assessed in terms of 
effectiveness via, what is commonly referred to in the ALN community as, the Five Pillars of Quality (Moore, 2002).

In 1997, Frank Mayadas, President of the Sloan Foundation Program for Learning Outside the Classroom, explained that if online education was to be effective, institutions must afford learners a level of quality that is representative of the host institutions' other programs (Moore, 2002). This meant that online courses should provide learners with levels of interaction and access equivalent to what they would expect in traditional settings. The five principals of quality that emerged from this philosophy are: Learning Effectiveness, Cost Effectiveness, Access, Faculty Satisfaction and Student Satisfaction.

This study focuses on Faculty Satisfaction, Student Satisfaction and certain relationships that exist between the two. As explained in the introduction, this is an area of research for which there are numerous calls in the literature and is of personal interest as well.

\section{Faculty Satisfaction}

\section{The Transformation from Traditional Teaching to ALN}

Within complex social organizations there are multiple roles that define the place and importance of the individual (Etzioni, 1964). These roles may consist of acts that fall within the cognitive, affective or social domains with the boundaries often overlapping. In some instances the roles are well defined through rule setting or traditional practice. In other cases, the roles are continuously evolving and are defined largely by peer or administrative expectations. However, it is important to note that these expectations can sometimes be rather amorphous and therefore frequently result in slow institutional transition as the roles are formalized. 
The role of faculty in institutions of higher education has traditionally been one that is defined by achievement in teaching, research and service (McKeachie, 1986). With respect to the teaching component, the cognitive aspect consists of those acts that foster the conveyance of knowledge. Affective aspects are related to those roles assumed by the instructor to influence the relationships within the classroom setting as well as the external but related relationships, such as mentoring and support, that are formed between students and instructor. Finally, the social functions related to the teaching component consist of policy enforcement and conflict resolution (Coppola, 2005).

However, when faculty are asked to develop and deliver online courses, conflicts with the traditional rubrics by which performance is assessed often arise. With respect to the act of teaching, Berliner (1988) notes that when interacting with technology many teachers revert to novice status. For the instructor who, through years of practice, has developed a teaching style that allows them to teach in a seamless, fluid manner, this reversion can often lead to the belief that technology-mediated learning is inferior to the traditional mode in which they are well versed (Bennett \& Lockyer, 2004). Specifically, the act of teaching can no longer be easily defined in terms of cognitive, affective and social roles. When moving to an online teaching environment, clearly defined managerial and gate-keeping roles emerge from the traditional cognitive and affective aspects of teaching (Coppola, 2005).

Collis and Nijhuis (2000) developed a two-part framework of managerial duties for the online instructor, using cross case analysis. The first of these duties is course planning which encompasses all of the design and development activities involved with putting a course online, including interfacing with those support and administrative staff 
that must be included in the process. The second managerial duty, leadership, consists of motivation and coordination of students through course design. Though traditionally addressed in the affective aspect of teaching, Collins and Nijhuis believe that leadership aspects need to be considered at the earlier course development level for online learning to be most effective.

With respect to gate-keeping, Coppola, Hiltz and Rotter (2002) reported that faculty found the planning requirements for development of an online course to be much greater than for traditional delivery. Issues such as access to administrative units, technical support staff, instructional consultants and specialized software/hardware all required well-managed collaboration and scheduling. This team-based approach to delivery differs dramatically from typical higher education teaching scenarios but is considered essential to the development of successful online course development.

From this analysis, it is apparent that the development and delivery of online courses creates a situation in which traditional organizational roles are challenged by the emergence of new and often ill-defined expectations. For faculty who have based their careers on traditional course development and teaching practices, there are often serious misgivings about and resistance to a transition to online courses (Kaminski \& Milheim, 2002; Botsch \& Botsch, 2000). In addition to concerns about the online medium itself, Thompson (2004) found that one of the largest barriers to faculty buy-in is the issue of increased work loads that are often associated with developing and teaching online courses.

Institutions that have developed successful, large scale online learning programs have done so by systematically addressing the needs of faculty as they transition from 
traditional to online teaching (Zotti, 2005). Though the mechanisms differ from institution to institution, practices that ensure adequate support for faculty in course preparation and course delivery, and promote participation in institutional matters related to ALN in general have been found to result in high levels of faculty satisfaction despite changes to their role expectations within the organization (Brown, 2003).

The institutional case studies that follow illustrate the importance of these types of support to program success. Despite their widespread acceptance in the ALN communities, some of these studies provide low levels of detail with respect to methodology and/or findings. Where information regarding methodology, data collection, survey details, findings, etc. were available, they were included in the following summaries. In many cases this was not possible as certain program evaluation techniques or specific findings are considered proprietary information and only synopses are available in the literature.

From a research perspective this is problematic in that grounded theory is currently based as much on opinion as data. However, cross case analysis, which is conducted at the end of the institutional reviews, does help to validate working assumptions of programmatic best practice.

\section{The University of Central Florida Experience}

In their program evaluation of the ALN initiative at the University of Central Florida (UCF), Hartman, Dzuiban and Moskal (2000) reported that faculty satisfaction and overall program success were rooted in the institution's broad based support program. Beginning with the Interactive Distributed Learning for Technology-Mediated Course Delivery 6543 (IDL6543) course, faculty are systematically exposed to 
increasingly complex strategies and applications for ALN development and teaching. At the lowest level, faculty experience online learning from a student perspective and share their perceptions of pedagogical techniques with their peers. This acts as the basis for individualized course design strategies, which are developed in a collaborative process with design team members who provide specialized instructional design and technical support.

Faculty become more comfortable with the design and delivery process when individualized training and support programs are available to assist faculty with the development of technical and/or pedagogical tools and strategies (Hartman et al., 2000). Regardless of the stage of expertise a faculty member may wish to achieve, there are available support mechanisms present that help counter feelings of isolation or frustration. In addition, peer support and research among faculty members provides for growth of both individuals and strategic initiatives.

When surveyed, $83.4 \%$ of UCF faculty described their experience with ALN as being satisfying (Hartman et al., 2000). 93.5\% believed that the quality of interaction with students was higher than in traditional classes and $93.6 \%$ indicated they would like to teach another ALN course. Combined, these findings point to a high degree of efficacy in the UCF initiative.

\section{The State University of New York Experience}

In their analysis of factors influencing faculty satisfaction with asynchronous learning and teaching in the State University of New York (SUNY) Learning Network (SLN), Fredrickson et al. (2000) describe the comprehensive support structure used to promote effective online faculty. The process begins with providing faculty with 
exemplary strategies and collaborative planning opportunities in a novice-mentor relationship. In this process, faculty are encouraged to develop a course structure that meets their perceived needs and is not dictated by the delivery system.

By working with instructional designers and media support staff, faculty are able to develop course materials that are representative of best practice from a pedagogical perspective while making use of those tools best suited for delivery of content and establishment of collaboration rich ALN (Fredrickson et al., 2000). At all phases of this process faculty have access to individualized technical assistance and peer collaboration. As an extension of the development process these faculty share the developed products to increase the exemplar base of best practice within the SLN.

When surveyed about overall satisfaction with the SLN program $69.5 \%$ of faculty said they were very satisfied, $30.5 \%$ said they were somewhat satisfied and none indicated that they were either not very satisfied or not satisfied at all (Fredrickson et al., 2000). With respect to perceived student performance in ALN $44.8 \%$ of faculty believed students performed better than in ALN and $43.8 \%$ believed there was no difference.

\section{The Virginia Tech Experience}

In the mid 1990's, Virginia Tech integrated the Faculty Development Institute (FDI) into their overall Instructional Development Initiative (IDI) to promote best practice among faculty with respect to technology integration in teaching (Moore, 2001). Using a four-year recurring model, the FDI hosts workshops that introduce faculty to exemplary models and promote collaborate project development. The emphasis is placed on practical issues of technology-enhanced teaching and long-term development of faculty based on gradual integration of technology into current teaching practices. 
In addition to the FDI, faculty receive ongoing technical support through the New Media Center (NMC) which provides access to hardware, software and individualized services to faculty engaged in the development process (Schwartz \& Phillips, 2003). Staffed by student assistants trained in the use of numerous technologies, the NMC provides a centralized location in which collaboration can occur and project specific support for areas of development in which faculty may not have the skills required for the completion of technology intensive course components.

From an institutional perspective, the FDI has been found to decrease faculty resistance to the use of technology, improve technology-enhanced teaching by faculty with varying degrees of expertise and meet the needs of faculty as they become engaged in increasingly sophisticated course development projects (Moore, 2001). The positive nature of all of these findings is attributed to the strong support structures offered through the FDI that offer both broad based support while allowing for personalized development on an as needed basis.

\section{The Colorado State University Experience}

Beginning in 2000, Colorado State University (CSU) undertook the development of an online bachelor's of arts program in general studies (Kaminski \& Milheim, 2002). The program was designed to meet the upper-level course requirement needs of nontraditional students through ALN offerings. The program began with identification of faculty and a survey of areas of need that were deemed essential for development of the program. Though many faculty had experience with teaching distance-based courses, few were familiar with web-based delivery. The areas identified in the needs survey were primarily related to technological support and instructional design of ALN. 
CSU responded by establishing a program that provided participating faculty with a multi-level support system (Kaminski \& Milheim, 2002). Top priority was given to instructional design support which focused on the use of course specific pedagogical strategies as well as digital audio, digital video, graphics, animation and other types of materials development. Each faculty member was also given access to student assistants to help with instructional research and data entry. In addition to these personalized services faculty became engaged in a collaborative evaluation process in which best practice across courses was continuously analyzed and project based workshops were conducted.

Because of high levels of faculty satisfaction and the overall success of the program, development and expansion of ALN at CSU continues to grow beyond the core program described (Kaminski \& Milheim, 2002). Ongoing collaboration between faculty and the administration is viewed, by CSU, to be the most effective means to ensure that the necessary support levels are maintained as this expansion occurs.

\section{The Brandon University Experience}

In August of 2000 Brandon University began developing online courses with the hope of creating outreach degree programs to residents of western Canada (Ferrazzi, 2003). Initially the program relied upon technology-savvy faculty using limited hardware and software, with plans of later expanding support services to include full-time pedagogical consultants and technical staff. Over the next 18 months, faculty continued to struggle with obtaining needed resources but few additional support structures were added by the administration. In addition, only minimal support services for students were made available and the bulk of technical support was provided by course instructors. As a 
result new faculty were reluctant to become engaged in online teaching and the cohort of early adopters did not substantially upgrade their courses. Overall satisfaction with the available support structures was extremely low and prospects of program expansion were $\operatorname{dim}$.

\section{Cross Case Analysis}

Each of the above case studies draws out potential cause and effect processes in the development of successful ALN through either purely qualitative or mixed methods analysis. As such, it is possible to group the findings within their respective processoriented analytical framework approaches (Patton, 2002). Next, if one considers the cross case analysis using analytical induction, Bernard (2000) contends that it is possible to extract universal causal generalizations across the groups. However, as noted prior to the review of institutional experiences, the type and quantity of information on cases and historical data are a limiting factor in this process.

Using this approach, it is first necessary to categorize the studies by positive and negative process development. With respect to the positive themes generated, the UCF, Virginia Tech, CSU and SUNY experiences all emphasize the need for strong support structures to achieve high levels of faculty satisfaction and then continue to explore specific categories of required support. The categories of support can be defined as: technical support and pedagogical guidance.

In all four cases pedagogical guidance consisted of the presentation of exemplars followed by collaboration with expert personnel and peers to establish and refine elements of best practice in ALN development. Though the mechanism varied from highly organized permanent staffing in the UCF and SUNY experiences to student 
worker supplemented structures at Virginia Tech and CSU, the need for continuing and individualized pedagogical and instructional design personnel was found to be a key component to faculty satisfaction in all cases. This finding is reinforced by examination of the Brandon University experience in which pedagogical guidance structures were non-existent and faculty became reluctant to engage in substantial development efforts.

As with pedagogical guidance, technical support was provided through different methods at UCF, Virginia Tech, CSU and SUNY. UCF and SUNY utilized higher levels of professional staffing while Virginia Tech and CSU relied more on a student-assistant model. However, the core functions of the supporters were found to be very similar; they all assisted faculty in individualized preparation of course materials and documents in order to allow for more sophisticated ALN than would have been possible had the institutions relied entirely on faculty empowerment. It should be noted that in the SUNY experience, the latitude afforded faculty was not as great as in the other cases, possibly as a result of the large number of faculty involved in the SLN. In contrast, the Brandon University experience again demonstrates that when this support element was missing faculty were reluctant to engage in the construction or substantial upgrading of ALN. Supporting this inductive analysis is Bishop's (2004) call for application of a systems approach to effective online teaching and learning. In her analysis of faculty and student satisfaction, Bishop examines the role of course interactions and feedback loops as key elements with respect to both groups. Bishop, Associate Dean for Administration in the Graduate School at University of Maryland University College (one of the largest ALN based programs in the world) and an effective practices editor for the Sloan Consortium, is considered a leading authority on ALN; therefore her work on the nature 
and relationship of these variables is given substantial weight in the ALN research community.

From a theoretical standpoint, it is possible to relate the elements of faculty satisfaction explained by Bishop to the technical support and pedagogical guidance mechanisms revealed in the analytical induction process. According to Green (1971), both substantive interactions and feedback are considered to be necessary if true teaching, as opposed to mere instruction, is to occur and are therefore considered to be pedagogical elements. Joyce, Weil and Calhoun (2004) contend that interactions that occur within the learning process are a function of pedagogy and Morrison, Ross and Kemp (2004) similarly agree that learning interactions are defined by planned activity elements of instructional design. Salmon (2002) explains that pedagogical practice is transformed into online learning environments via the use of technology. Therefore the interactions and feedback loops discussed by Bishop can be, in a larger context, viewed as resulting from pedagogical design and technology based implementation.

In a conversation related to this work, Bishop (personal communication, October 20, 2005) expressed her belief that interaction and feedback within ALN can be viewed as manifestations of both the pedagogical design basis and the technology used in creation of the ALN. Bishop also agreed that for student satisfaction to emerge in ALN, satisfactory support structures would need to be in place for seamless interactions to occur within the course.

Through triangulation (Yin, 1994) of the cross case inductive analysis, existing literature that addresses the nature of pedagogical practice and Bishop's work in the field, the validity of faculty satisfaction being a function of technical support and pedagogical 
guidance is reinforced. This triangulation provides a grounded theory basis for the use of technical support and pedagogical guidance provided to faculty as predictor variables in this study.

\section{Student Satisfaction}

The overwhelming reason for taking online courses is convenience. In a study conducted for the National Center for Education Statistics (2003), over 95\% of respondents indicated flexibility and schedule fit as being of importance when choosing to enroll in an online course. However, as students were allowed to select multiple reasons this study is somewhat misleading. A similar study of over 40,000 students in the SLN, that allowed for selection of only one reason, revealed schedule flexibility to be the primary reason for enrollment 45 to $55 \%$ per semester from the Spring of 2000 to the Fall of 2002 (Shea et al., 2002).

Beyond the convenience and scheduling factor, other research reveals what course elements and activities produce the highest levels of student satisfaction. DiPaolo (2001) lists 20 criteria related to student satisfaction in ALN. Of those not related to scheduling and career specific goals the most important are:

1. Well-designed, engaging, intellectually challenging and continuously updated courses which connect the transfer of learning to doing.

2. Emphasis on interactive, goal-oriented, problem-based learning using real, vivid and familiar examples.

3. Short modules which can be bundled into an interactive learning experience.

4. Participation in a "connected learning community" by active engagement and collaboration with instructors, tutors, peers and experts. 
5. To collaborate by working in geographically-dispersed learning groups.

6. Continuous, prompt and meaningful feedback.

7. Outstanding e-support for student services with a focus on "student as consumer."

With respect to engagement, interactivity and feedback, Shea et al. (2003) investigated the relationship between student satisfaction and Chickering's principles of good practice. The study examined whether student satisfaction resulted from course structures that promoted: student-faculty contact, cooperation among students, active learning, prompt feedback, emphasized time on task, communicated high expectations and respected diverse talents/ways of learning (Chickering and Gamson, 1987). The study revealed significant correlations between student satisfaction and interaction with the instructor as well as student satisfaction and interaction with other students (Shea et al., 2003).

At the University of Maryland University College (UMUC), two internal studies of student satisfaction have been conducted. In the first study a multivariate analysis, by Carswell and Fleming, revealed there was a high correlation between student satisfaction with the course and: (a) useful feedback, (b) effective communication, and (c) support and guidance (Bishop, 2004). There was also a high correlation found between students' likelihood of recommending a faculty member and: 1) effective communication, 2) support and guidance and 3) accessibility. In the second UMUC study, Abdul-Hamid, found significant correlations between students' likelihood to recommend a faculty member and: (a) interaction, and (b) useful feedback (Bishop, 2004). 
Connecting Faculty and Student Satisfaction in the OILM

Effective ALN are based upon the collaborative activities that occur within the OILM framework (Benbunan-Fich et al., 2005; Moore, 2002), thereby making it essential to understand what defines collaborative learning. From a theoretical perspective, Green (1971) defines the acquisition of knowledge as a process in which facts, evidence and beliefs interact and are modified by groups of learners and those providing the evidence and interpretations of the facts. Freire (2004) defines this type of knowledge coconstruction as problem posing as it requires continual input and modification at various levels to achieve consensus solutions to a given problem. Using these two models as a foundation, it becomes possible to understand interaction and feedback as resulting both from the actions of those who initiate the learning activities, or create a problem posing situation, and from the actions of the learners themselves.

A working model of this dualistic interpretation of interaction and feedback can be found in the principle of Chaordic Theory as outlined Hock (1999) who argues that given a catalyst for origination and only loosely established boundaries, individuals will continually solve problems and simultaneously create new ones. Within this cycle, the roles of the individual may change with respect to resolving a given problem, but their contribution to the overall goal is related to the group dynamic that emerges. In this type of system, the process of goals being initially established by an instructor and interaction thereby initiated would be a function of the pedagogical and technical design elements of ALN construction and delivery. The process in which groups of learners work with each other and the instructor to find solutions would produce further degrees of interaction and 
continuous feedback loops, such as those envisioned by Benbunan-Fich et al., (2005) and Hiltz and Shea (2005), thereby becoming the elements most closely associated with student satisfaction .

Through factorial analysis of 2036 end-of-course surveys, Shea and colleagues found that instructional design/organization and facilitation of discourse account for 70 percent of the variance in ALN student satisfaction (Shea et. al. 2005). Earlier theoretical constructs upon which this research was based defined these two elements as being critical to establishing teaching presence in ALN. Specifically, instructional design and organization consists of the following indicators:

- $\quad$ setting curriculum

- designing methods

- $\quad$ establishing time parameters

- utilizing the medium effectively

- establishing netiquette

(Anderson, Rourke, Garrison \& Archer, 2001)

Indicators that define effective facilitation of discourse are:

- identifying areas of agreement and disagreement

- $\quad$ seeking to reach consensus and understanding

- encouraging, acknowledging, and reinforcing student contributions

- $\quad$ setting the climate for learning

- drawing in participants and prompting discussion

- assessing the efficacy of the process

(Anderson, Rourke, Garrison \& Archer, 2001)

Clearly these are all indicators that would be impacted by the degree of technical support and pedagogical guidance provided to ALN faculty. However, Shea and colleagues (Shea et al. 2005) did not examine the levels of support to faculty that 
produced high levels of student satisfaction with respect to the above variables.

Therefore, while we have some degree of insight into outcome and effect, initial input in the form of support and student satisfaction remains unexplored.

In a conversation related to this linkage, Shea (personal communication, November 17, 2005) agreed that any element impacting faculty satisfaction should produce measurable changes in student satisfaction, via the OILM feedback loops. Shea went on to state that exploration of such correlations had been considered in the SLN studies; however, the initial program evaluations were so lengthy that this was one of several elements that were not addressed. He also expressed his belief that this type of study should be meaningful and contribute significantly to the existing body of research. Considering Shea's prominent role in the ALN research community, his opinion was given substantial weight in the development of this study.

Faculty Support and Student Satisfaction at West Virginia University's College of Human

\section{Resources and Education}

A qualitative study of HR\&E faculty satisfaction revealed that ongoing technical support was the most important factor influencing satisfaction in ALN development and delivery ( $\mathrm{n}=6$ of 11$)$ (Ice $\&$ Phillips, 2006). Access to pedagogical guidance and instructional designers with a background in ALN was considered the second most important factor ( $\mathrm{n}=3$ of 11) (Ice \& Phillips, 2006).

With respect to the need for ongoing technical support, one faculty member stated:

The technology is changing so fast and we have to try to keep up with it all. I just can't do that and do everything else I need to do as well. If it wasn't for 
the support I get with designing the courses I don't think I would be teaching them. There are things like video that students want and those things make the course better too. But, I don't know how to do them and again, I don't have the time. So if I want those things in my course that makes it good for students I need that design [support] that makes a class good all the way around.

This faculty member later stated:

I know these things [active content] are important because my students comment on them in their evaluations and how this makes my classes better than other online courses they have taken. Again, though, I just don't know how to do these things and wouldn't take the time to try and do them if I didn't have access to the people I needed to make it happen.

These comments are representative of those made by faculty who put the highest value on technical support relative to satisfaction. Of the six who ranked technical support as being most important, five later followed up with comments related to the importance of advanced design elements, which they felt they were currently incapable of producing without assistance, as being directly related to how satisfied students were with their courses.

With respect to pedagogical guidance one faculty member stated:

I've taught in the traditional classroom for over 35 years and now I am trying to learn to teach online. I see some [other instructors] who just post up a PDF with their syllabus on it and then some lecture notes the same way. They just want students to do an assignment and submit it. That's not really teaching. That's 
more like the old correspondence work that's been with us forever. That's not what I want.

With the courses that I have up there now, I've had someone right there with me at each phase helping me think through the content and making it so it works for the students. By works I mean it creates this place that's like a real place where they get together and learn and do things together; where they have interactions. I like that and that's what I think these online classes really should be. That said, I really am not wired to think like that. Like I said, I have taught in the traditional classroom all these years and I just have a difficult time transitioning. If I didn't have the help making these activities meaningful then I don't think my courses would be very meaningful.

In response to a follow-up question this faculty member related the importance of pedagogical guidance to student satisfaction by saying:

You know, at the end of the courses I've gotten these evaluations in and in the [qualitative] reply sections I've seen these comments where students talk about feeling like they were really part of a class. They said things like they felt like they connected with each other and me. I didn't really know what to make of that for a while, then after I thought about it I thought about what they were doing in some of the other classes where maybe they just did and assignment and turned it in. There was no common experience there.

This is what I meant about not thinking in a way that is best for developing online courses. It's like you are focusing on every detail and thinking three or four steps ahead of the students, but you have to do it before the 
interactions ever start. In the real classroom I know how to do that; you learn to do that on the spot. I don't know that I could really anticipate that... laying out a course months before it ever takes place. So, if I want my students to have those types of experiences and things they like then I need the kind of help I've had in building my courses so far. I need that type of ... forward thinking and I think my students do too.

Of the three instructors who placed the highest value on pedagogical guidance relative to satisfaction all expressed concern about their ability to transition from a faceto-face learning situation to ALN and maintain the integrity of their courses. In all three cases this theme was expressed in terms of student learning and how valuable faculty believed students would find their courses. Specifically, these faculty believed that absent pedagogical guidance in the design phase they would be unable to design effective courses and that students would find such courses to have little, if any, value. 


\section{CHAPTER 3}

\section{METHOD}

This research study sought to investigate the relationship between technical support and pedagogical guidance provided to faculty and the satisfaction of students enrolled in asynchronous learning networks (ALN) at West Virginia University's (WVU) College of Human Resources and Education (HR\&E). This section describes the participants, research question, cycle of events, instrumentation, data collection process and data analysis.

\section{Participants}

Two sets of subjects were involved in this study. The first set consisted of 15 online instructors at WVU's College of HR\&E. The second set consisted of students enrolled in courses taught by the eleven aforementioned instructors.

\section{Instructors}

The online instructors consisted of 15 HR\&E faculty, adjunct faculty and teaching assistants from the departments of Advanced Educational Studies (AES) and Educational Theory and Practice (ETP). ALN experience levels varied from early adopters who have taught multiple online courses to first time online instructors. Employment status included graduate teaching assistants, adjunct faculty and full-time faculty. Table 2 illustrates the experience levels and status of the subjects. 
Table 2

Employment Status and ALN Teaching Experience of Faculty

\begin{tabular}{|c|c|l|c|}
\hline Subject Number & $\begin{array}{c}\text { Total Online Courses } \\
\text { Previously Taught }\end{array}$ & Employment Status & $\begin{array}{c}\text { Courses Used in } \\
\text { Study }\end{array}$ \\
\hline 1 & 4 & Professor & 3 \\
\hline 2 & 8 & Associate Professor & 3 \\
\hline 3 & 7 & Professor & 4 \\
\hline 4 & 4 & Assistant Professor & 1 \\
\hline 5 & 2 & Adjunct & 1 \\
\hline 6 & 6 & Associate Professor & 2 \\
\hline 7 & 8 & Professor & 2 \\
\hline 8 & 3 & Teaching Assistant & 1 \\
\hline 9 & 4 & Assistant Professor & 2 \\
\hline 10 & 5 & Assistant Professor & 1 \\
\hline 11 & 4 & Professor & 3 \\
\hline 12 & 7 & Professor & 2 \\
\hline 13 & 2 & Assistant Professor & 1 \\
\hline 14 & 1 & Adjunct & 1 \\
\hline $15^{*}$ & 6 & Professor & $3^{*}$ \\
\hline
\end{tabular}

*Data for instructor 15 were excluded from the final analysis of data for reasons

discussed later in this chapter.

The selection of instructors was based on previous usage of the assessment instrument in their classes. As previously discussed, no standard student evaluation instrument is being utilized at the university or college level, therefore only a portion of instructors were using the student satisfaction instrument that was required for this study. Of those using the instrument, $100 \%$ agreed to share their data.

\section{Students}

Students $(n=519)$ in the 30 classes for which the instrument was administered were all pursuing either master's or doctoral level studies. The number of students who were taking courses for use in programs at other institutions and transferring credits from WVU is unknown, however, since HR\&E online courses have received little marketing 
or publicity it can be assumed that the vast majority students considered WVU to be their home institution.

\section{Research Questions}

This study used multiple regression analysis to answer the following research questions:

1. What is the relationship between technical support and pedagogical guidance provided to faculty (the predictor variables) and student satisfaction with instructional design / organization (the criterion variable) in ALN?

2. What is the relationship between technical support and pedagogical guidance provided to faculty (the predictor variables) and student satisfaction with facilitation of discourse (the criterion variable) in ALN?

\section{Research Design}

This study used quantitative statistics in a correlation research design. The study sought to explain the impact of two predictor variables on two criterion variables. A relationship approach was used (Mertens, 2005). The predictor variables were hours of technical support and pedagogical guidance provided to faculty. The criterion variable was student satisfaction, as assessed through two scales assessing instructional design/organization and facilitation of discourse. Both predictor and criterion variables are discussed in detail in the instrumentation section of this chapter.

Instructional design/organization and facilitation of discourse are the two measures of teaching presence that Shea and colleagues found to account for $70 \%$ of the variance in teaching presence (Shea, et al., 2005). Other indicators of teaching presence have yet to be identified in the literature. 
Data were collected from 30 online courses offered at the College of HR\&E, by 15 instructors, from the Spring Semester of 2005 through the Spring Semester of 2006. From the 30 courses student satisfaction surveys (SSS) were gathered from 519 students. The 30 courses, from which student satisfaction data were obtained, comprised all of the online courses at HR\&E using the SSS.

To determine if the technical support and pedagogical guidance provided to faculty had predictive value with respect to student satisfaction a three step process was be used. In the first step, bivariate scatter plots were be generated to determine if a visually apparent regression pattern (non-significant distribution, linear, curvilinear or bicubic) exists.

In step two, the scatter plot of technical support and instructional design/organization was superimposed on the scatter plot of pedagogical support and instructional design/organization to determine if an interaction exists. The same type of superimposition was conducted with the scatter plot of technical support and facilitation of discourse and the scatter plot of pedagogical design and facilitation of discourse.

Based on the findings of steps one and two, appropriate regression analyses were conducted. As a precautionary measure, a test of covariance between number of courses previously taught by instructors and the measures of student satisfaction was also be conducted. 


\section{Instruments}

Methodology for Ascertaining Hours of Technical Support and Pedagogical Guidance

\section{Provided to Faculty}

As part of the study of HR\&E faculty discussed in the literature review (Ice \& Phillips, 2006), faculty were asked whether they had attended the Faculty Academy and if they had received any additional technical support or pedagogical guidance for the development and delivery of online course. If any additional support or guidance was noted, they were asked about the source and number of hours. If faculty were unsure of the number of hours the provider was contacted for clarification.

During the Faculty Academy, faculty were provided with 25 hours of technical support and 15 hours of pedagogical guidance. Hours of recorded technical support and pedagogical guidance were added to reported hours of technical support and pedagogical guidance. These figures served as the base hours of technical support and pedagogical guidance.

In May of 2006 faculty were asked to report any additional technical support and pedagogical guidance received since the previous interview. If faculty were unsure of the number of hours the provider was contacted for clarification. These hours were then added to the base hours previously calculated.

\section{Student Satisfaction Survey}

As previously noted, no standard evaluation instrument had been used by online instructors in the College of HR\&E. In response to the need for a common instrument, as reported by faculty who I provided support to, I researched available instruments that were in use by prominent universities engaged in ALN delivery in the Spring of 2005. 
The SSS was derived from three well recognized student satisfaction surveys used in ALN research. The first instrument was used by the New Jersey Institute of Technology and was developed by Hiltz (1996). The second instrument was used at the New Jersey Institute of Technology and was developed by Spencer (2000). The third instrument was used at Penn State's World Campus and was developed by Melody Thompson (2000).

The Hiltz instrument contains a combination of 123 Likert scale and open ended items, the Spencer instrument contains a combination of 66 Likert scale and open ended items and the Thompson instrument contains a combination of 38 Likert scale and open ended items related to overall student satisfaction as well as program specific questions. The items in each instrument were compared and common themes and questions were extracted for use in this survey. The survey developed consisted of 48 items. Program specific items were omitted. Each of these items was then reviewed to determine if they satisfactorily addressed student satisfaction with standards developed in a review of the literature: overall course design, clarity of course requirements, facilitation of learning, adequacy of content and development of constructivist oriented learning communities (Appendix A).

The SSS was piloted in two ETP courses during the Spring of 2005. Afterwards it was presented for comment at the 2005 Faculty Academy. No revisions were suggested and broader use occurred in subsequent semesters across two of the four departments within HR\&E, Advanced Educational Studies (AES) and ETP.

\section{Instructional Design and Organization Subscale}

The six items used in the instructional design and organization subscale (IDOS) were selected from the student satisfaction survey (SSS). The items in this subscale were 
intended to represent elements of instructional design and organization employed in online learning environments. Items were selected based on how closely they matched a similar instrument developed by Shea and colleagues (Shea, Swan, Li \& Pickett, 2005) which assessed setting curriculum, designing methods, establishing time parameters, utilizing the medium effectively and establishing netiquette; indicators of effective instructional design and organization as defined by Anderson, Rourke, Garrison and Archer (2001).

With a Chronbach's Alpha of 0.94 (Shea, Swan, Li \& Pickett, 2005) and being designed by three of the leading researchers in the field, the instructional organization and design instrument designed by Shea and colleagues is considered to be both highly reliable and valid. The items selected for the IDOS, used in this study, are thematically similar to those in the Shea instrument and vary only slightly in terms of wording.

Each item asked students to respond using a five point Likert scale with answers consisting of Strongly Disagree, Somewhat Disagree, Neutral, Somewhat Agree and Strongly Agree. Responses were converted to a numerical scale with Strongly Disagree = 0, Somewhat Disagree $=1$, Neutral $=2$, Somewhat Agree $=3$ and Strongly Agree $=4$. Responses for the six items were summed and a possible range of $0-24$ recorded for each student. (Instructional Design and Organization subscale attached in Appendix B.)

\section{Facilitation of Discourse Subscale}

The six items used in the facilitation of discourse subscale (FDS) were selected from the SSS. The items in this subscale were intended to represent elements of facilitation of discourse. Questions were selected based on how closely they matched a similar instrument developed by Shea and colleagues (Shea, Swan, Li \& Pickett, 2005) 
which assessed identifying areas of agreement and disagreement, seeking to reach consensus and understanding, encouraging, acknowledging, and reinforcing student contributions, setting the climate for learning, drawing in participants and prompting discussion and assessing the efficacy of the process; indicators of effective facilitation of discourse as defined by Anderson, Rourke, Garrison and Archer (2001).

With a Chronbach's Alpha of 0.97 (Shea, Swan, Li \& Pickett, 2005) and being designed by three of the leading researchers in the field, the facilitation of discourse instrument designed by Shea and colleagues is considered to be both highly reliable and valid. The questions selected for the FDS, used in this study, are thematically similar to those in the Shea instrument. Wording is somewhat less concise, as compared to the Shea instrument, than was the case with the instructional design and organization subscale.

Each item asked students to respond using a five point Likert scale with answers consisting of Strongly Disagree, Somewhat Disagree, Neutral, Somewhat Agree and Strongly Agree. Responses were converted to a numerical scale with Strongly Disagree $=$ 0 , Somewhat Disagree $=1$, Neutral $=2$, Somewhat Agree $=3$ and Strongly Agree $=4$. Responses for the six items were summed and a possible range of $0-24$ recorded for each student. (Facilitation of Discourse Subscale attached in Appendix C.)

\section{Validity of Subscales}

The subscales upon which those used in this study were based were created by three of the leading researchers in the teaching presence field in conjunction with Anderson, co-creator of the theoretical model of teaching presence (Shea, et al., 2005). However, some concern existed as the items used in this study were only thematically similar to the aforementioned subscales. Discrepancies existed with respect to exact 
wording. To address this concern, Swan, one of the creators of the original subscales, was contacted. In Swan's opinion, even though some minor differences existed between the subscale items in this study and the ones created by her group she believed that the items were still sufficient for purposes of detecting correlations in this study (personal communication, March 12, 2006). Given Swan's stature in the ALN research community I believe that the subscale items used in this study are sufficiently valid for detecting the suspected relationship.

As a precautionary measure, the instruments were presented to a panel of three expert judges for validation. One was a faculty member in the program of Instructional Design Technology at WVU; the second was an instructional designer employed by WVU's Instructional Technology Resource Center; and the third was a faculty member in the School of Education at Virginia Tech. Each of these individuals had extensive experience with instructional design in the online environment and assessment procedures.

The panel of experts were asked to evaluate if the instrument adequately measured student satisfaction with respect to instructional design/organization and facilitation of discourse. The judges unanimously agreed that the items were valid and that the preceding items had been adequately sampled.

\section{Reliability of Subscales}

As previously discussed, the student satisfaction survey was first piloted in two ETP courses during the Spring of 2005. Internal consistency for the instructional design/organization and facilitation of discourse subscales was calculated using SPSS software. This yielded Cronbach's alphas (Cohen, Cohen, West \& Aiken, 2003) of 0.92 
for the instructional design/organization subscale and 0.91 for the facilitation of discourse subscale.

The difference in Cronbach's alphas between these subscales and those developed by Shea and colleagues is likely attributable to variations in wording as no thematic differences are present. Despite these differences the subscales are still considered quite reliable.

\section{Data Collection}

From Spring of 2005 thru Spring 2006, 15 HR\&E instructors used the student satisfaction survey in a total of 30 courses. The data for each were exported from WebCT Vista to an Excel spreadsheet. After obtaining consent and copies of the surveys from each of the instructors the data for the instructional design/organization and facilitation of discourse subscales were isolated. Extant data were then converted to $0-24$ point continuous scales are described above. These data were entered into the Statistics Package for the Social Sciences (SPSS) as the criterion variable.

To determine the predictor variables of technical support and pedagogical guidance, data from the Fall 2005 study of faculty satisfaction were reviewed. Hours for each type of support were recorded for faculty members. Faculty members were then asked to verify the hours of support provided and asked if any additional support had been needed during the Spring of 2006.

Hours of support were then referenced with the semesters in which courses were offered. These data sets were then entered into SPSS as the predictor variable for the corresponding student satisfaction scores on both subscales. 


\section{Procedure}

As no grounded theory existed to suggest the nature of the regression line, bivariate scatter plots were generated, from the data entered into SPSS, to determine the shape of regression lines on each subscale. This procedure is suggested by Mertens (2005) and Cohen et al. (2003) when it is impossible to predict in advance the type of regression analysis that will need to be performed. As discussed in the literature review, there is currently no other research related to this topic, therefore, the generation of bivariate scatterplots would be considered appropriate. Visual analysis confirmed the linear nature of the correlation.

An example of this procedure can be seen in Figure 2 below. This figure illustrates the regression line generated from a bivariate scatterplot of the relationship between pedagogical guidance and instructional design / organization. 


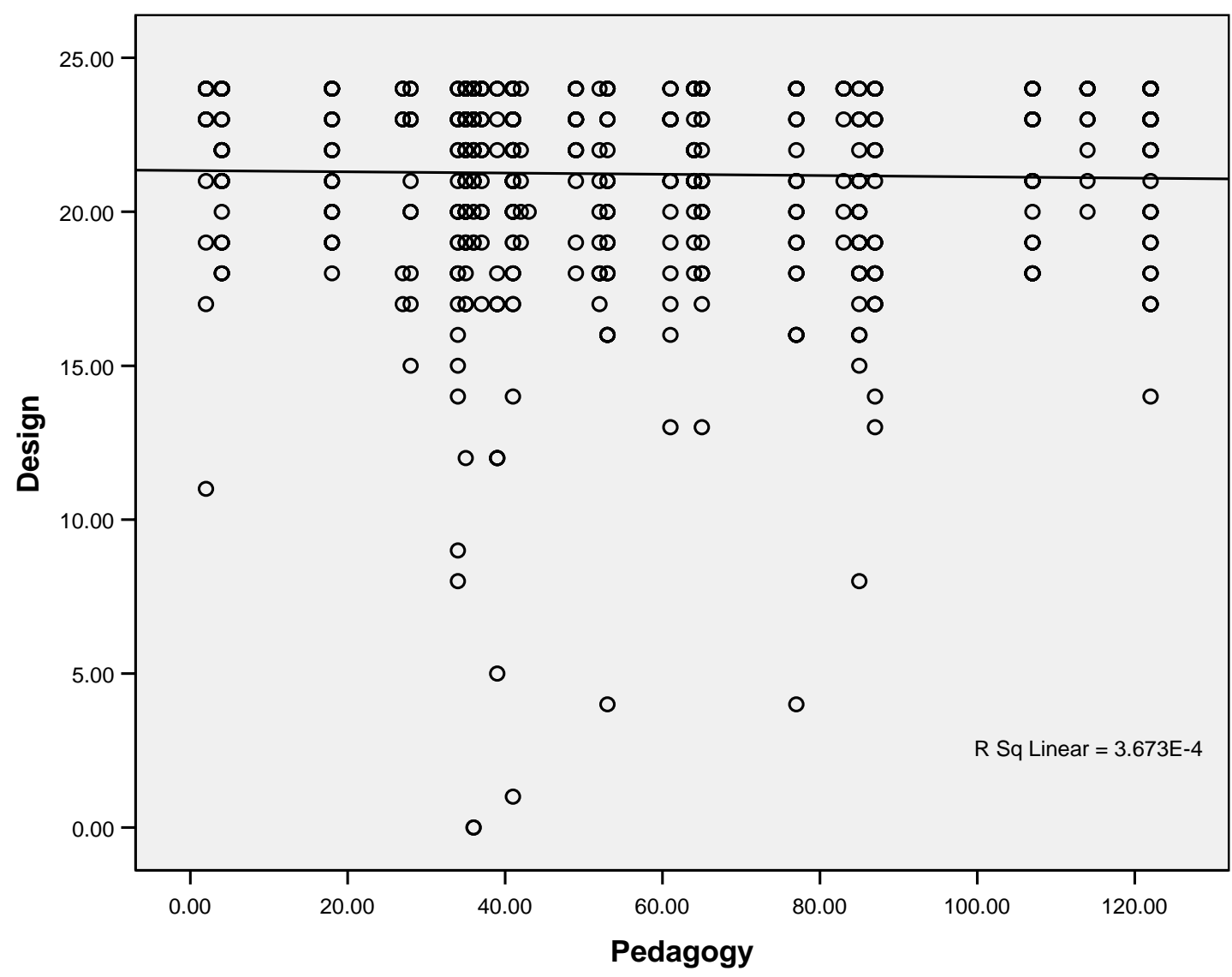

Figure 2. Bivariate scatterplot of the relationship between pedagogical guidance and instructional design / organization.

Similar bivariate scatterplots were also generated for the relationships between: 1 . technical support and instructional design / organization, 2. number of courses taught and instructional design / organization, 3. technical support and facilitation of discourse, 4. pedagogical guidance and facilitation of discourse, and 5. number of courses taught and facilitation of discourse. The regression lines generated in these bivariate scatterplots produced regression lines with a degree of linearity similar to the one depicted in Figure 2.

To ensure that confidence intervals and significance test were not compromised it was necessary to check for homoscedasticity of residuals (Cohen et al., 2003). This was 
done using the modified Levene's test. The null hypothesis was rejected in all six sets of modified Levene's tests.

In accordance with suggestions made by Cohen et al. (2003), means plots were examined to determine if any outliers may have compromised homoscedasticity of residuals. Figure 3, below, is representative of the six means plots generated.

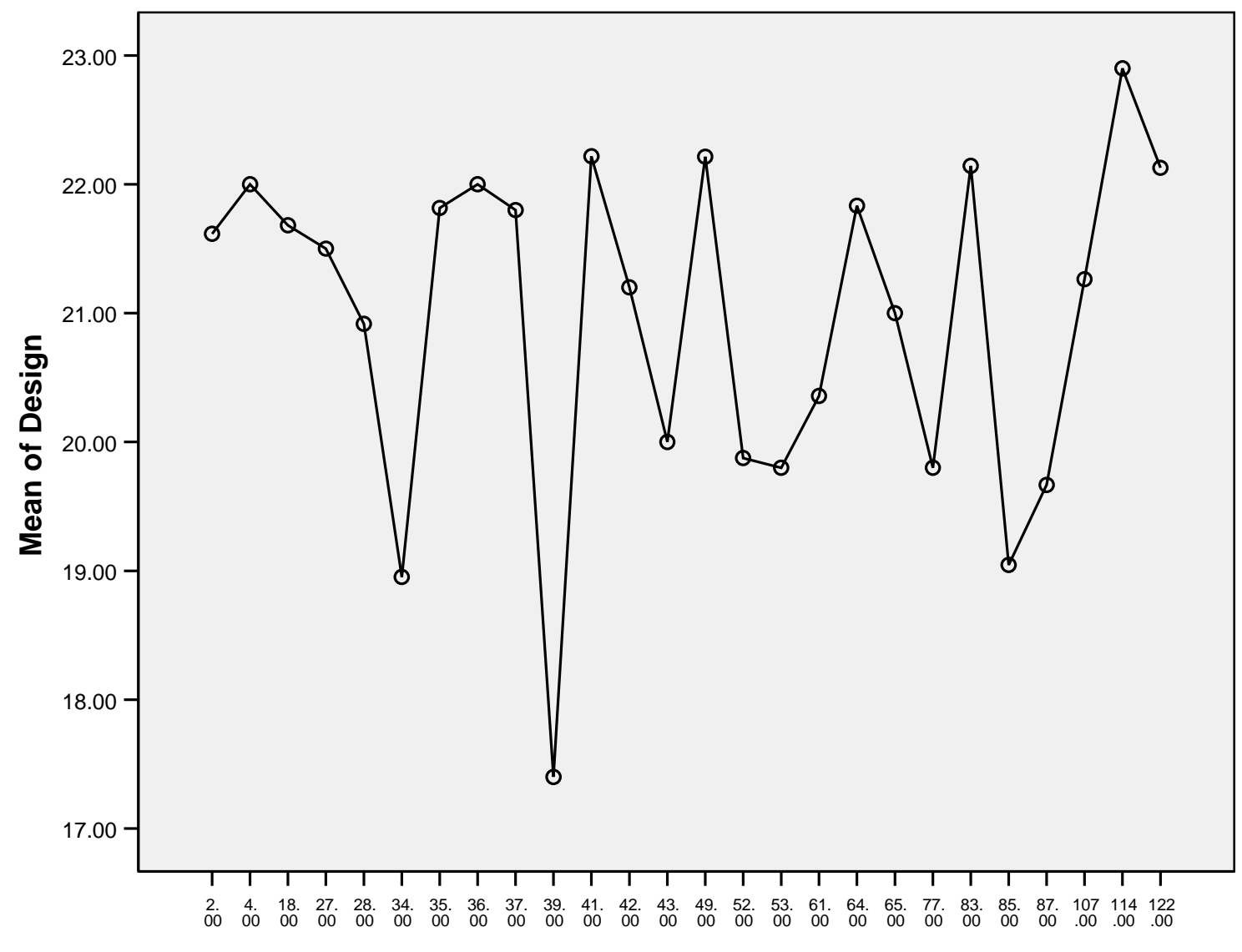

Pedagogy

Figure 3. Means plot of the relationship between pedagogical guidance and instructional design / facilitation

In each of the six means plots three nodes appeared to be significantly lower than the other data sets. Upon closer inspection it was determined that all three of these data sets were related to instructor 15 . In accordance with generally accepted procedures in 
regression analysis (Cohen et. al, 2003) the data for this instructor were removed and both the bivariate scatterplots and Levene's tests were rerun to determine if the suspected outlier had negatively impacted homoscedasticity of residuals.

No significant difference in the six bivariate scatterplots was detected after removal of the outlier. Confidence intervals and significance test were not compromised when the series of Levene tests were rerun. The null hypothesis was not rejected in any of the six Levene tests after removing the outlier.

In accordance with accepted procedure (Cohen et al., 2003), the outlier data were removed. Multiple regression analysis was then conducted using SPSS.

The regression analysis was conducted to answer the following research questions:

1. What is the relationship between technical support and pedagogical guidance provided to faculty (the predictor variables) and student satisfaction with instructional design / organization (the criterion variable) in ALN?

2. What is the relationship between technical support and pedagogical guidance provided to faculty (the predictor variables) and student satisfaction with facilitation of discourse (the criterion variable) in ALN?

\section{Limitations}

This study is subject to six limitations. These are discussed in the following subsections.

\section{Small Sample Size}

Though the number of student surveys used in this study $(n=519)$ was relatively large, the number of faculty $(n=15)$ was not. A larger sampling of faculty would have 
been preferable, however, the participants were limited, by necessity, to those using the SSS developed for use at WVU's College of HR\&E.

\section{Homogeneity of Participants}

As with sample size, the distribution of participants was limited to instructors using the SSS developed for use at WVU's College of HR\&E and students in their courses. Ideally, the sample would have included both instructors and students from multiple colleges within WVU. However, since each college, within WVU, has different training and support programs the findings would not have been meaningful.

\section{Previous Training in Online Course Development and Teaching}

As described in the review of literature section and earlier in this section, hours of technical support and pedagogical guidance were derived from the Faculty Academy initiative and ancillary support related to the Faculty Academy. This initiative has been in place at HR\&E since 2002. However, prior to this date, other development and training initiatives have been offered at HR\&E, including the Trek 21 initiative. These programs preceded and informed the Faculty Academy initiative in that they sought to provide faculty with support and skill development for designing and delivering online courses.

A survey of faculty participating in this study indicated that six had participated in these earlier initiatives. This is problematic as it was not possible to determine the level of previous technical support and pedagogical guidance provided to these faculty. However, some of this effect may be accounted for by examining the suspected copredictor, number of online courses previously taught.

In addition, there should be some degree of skills transference present in the portion of the Faculty Academy in which faculty share and critique content in an open 
dialogue. If so, then some of the effect of previous training among a subset of faculty might be minimized via the collaboration process.

\section{Skills Acquired Through Informal Processes}

As with the issue of previous training, this study does not account for skills acquired by faculty through informal processes. Such processes would include self-taught skills, skills gained via independent reading and skills gained through attending conferences. Again, as with the issue of previous training, some of this effect may have been minimized in Faculty Academy collaboration activities. Similarly some of this effect may be accounted for by examining the suspected co-predictor, number of online courses previously taught.

\section{Subscale Item Discrepancies}

As described previously, in the validity of subscales subsection, the subscales for satisfaction with instructional design / organization and facilitation of discourse differed from those developed by Shea and colleagues (Shea et al., 2005). Despite being very

similar thematically, some discrepancies exist in the wording of individual items. Use of the precise items developed by Shea and colleagues would have been preferable.

However, since data collection for this study ended, a new survey using the precise items has been used by six of the same faculty involved in this study. While the sample size for this data is small $(\mathrm{n}=93)$ there is less than $5 \%$ variation in the means between the satisfaction scores using the new items and satisfaction scores generated using the subscales in this study. Therefore, it appears, at this point, unlikely that any significant difference would have resulted from using the satisfaction subscales designed by Shea and colleagues. 


\section{Measurement of Technical Support and Pedagogical Guidance}

Technical support and pedagogical guidance were measured in quantitative terms; hours of each that were provided to faculty. While descriptors of what occurred in the Faculty Academy and ancillary support have been described previously this study did not examine how each of these variables might have impacted student satisfaction in isolation.

However, this study should still be considered important as many support initiatives, including the Faculty Academy, are designed based on an hours of contact approach. Therefore, it is useful to determine if this approach is successful in generating both high levels of faculty and student satisfaction in ALN. 


\section{CHAPTER 4}

\section{RESULTS}

In this chapter, results are reported on data collected and analyzed to answer the

Research Questions presented in Chapter 3. The research questions sought to determine:

1. What is the relationship between technical support and pedagogical guidance provided to faculty (the predictor variables) and student satisfaction with instructional design / organization (the criterion variable) in asynchronous learning networks (ALN)?

2. What is the relationship between technical support and pedagogical guidance provided to faculty (the predictor variables) and student satisfaction with facilitation of discourse (the criterion variable) in asynchronous learning networks (ALN)?

This chapter organizes the data by starting with a summary of hours of technical support and pedagogical guidance provided to faculty members by semester. Descriptive statistics are then used in the presentation of survey data. Finally, data from the two multiple regressions, described in the research questions, are presented. When appropriate, tables, graphs and diagrams are used to better illustrate the data.

\section{Participants}

Two sets of subjects were involved in this study. The first set consisted of 15 online instructors at WVU's College of HR\&E. The second set consisted of students enrolled in courses taught by the 15 aforementioned instructors.

\section{Instructors}

As described in the methods section, data for one of the instructors was removed because it was considered an extreme outlier. For the remaining 14 instructors hours of 
technical support and pedagogical guidance are displayed by semester. Data are presented for only those semesters in which instructors were engaged in teaching online courses.

Table 3

Cumulative Hours of Technical Support and Pedagogical Guidance Provided to Faculty

Who Taught Online Courses During the Spring Semester of 2005

\begin{tabular}{|c|c|c|c|}
\hline Subject Number & $\begin{array}{c}\text { Online Courses } \\
\text { Taught (Prior to } \\
\text { Spring 2005) }\end{array}$ & $\begin{array}{c}\text { Cumulative Hours } \\
\text { of Technical } \\
\text { Support }\end{array}$ & $\begin{array}{c}\text { Cumulative Hours of } \\
\text { Pedagogical } \\
\text { Guidance }\end{array}$ \\
\hline 1 & 1 & 79 & 52 \\
\hline 2 & 1 & 78 & 107 \\
\hline
\end{tabular}

Table 4

Cumulative Hours of Technical Support and Pedagogical Guidance Provided to Faculty

Who Taught Online Courses During the Summer Semesters of 2005

\begin{tabular}{|c|c|c|c|}
\hline Subject Number & $\begin{array}{c}\text { Online Courses } \\
\text { Taught (Prior to } \\
\text { Summer 2005) }\end{array}$ & $\begin{array}{c}\text { Cumulative Hours } \\
\text { of Technical } \\
\text { Support }\end{array}$ & $\begin{array}{c}\text { Cumulative Hours of } \\
\text { Pedagogical } \\
\text { Guidance }\end{array}$ \\
\hline 2 & 2 & 82 & 114 \\
\hline 3 & 2 & 52 & 27 \\
\hline 4 & 2 & 93 & 64 \\
\hline 5 & 1 & 10 & 36 \\
\hline 6 & 4 & 71 & 49 \\
\hline
\end{tabular}


Table 5

Cumulative Hours of Technical Support and Pedagogical Guidance Provided to Faculty

Who Taught Online Courses During the Fall Semester of 2005

\begin{tabular}{|c|c|c|c|}
\hline Subject Number & $\begin{array}{c}\text { Online Courses } \\
\text { Taught (Prior to Fall } \\
2005)\end{array}$ & $\begin{array}{c}\text { Cumulative Hours } \\
\text { of Technical } \\
\text { Support }\end{array}$ & $\begin{array}{c}\text { Cumulative Hours of } \\
\text { Pedagogical } \\
\text { Guidance }\end{array}$ \\
\hline 1 & 2 & 88 & 61 \\
\hline 2 & 3 & 91 & 122 \\
\hline 3 & 3 & 59 & 34 \\
\hline 4 & 3 & 104 & 77 \\
\hline 5 & 2 & 15 & 42 \\
\hline 6 & 5 & 83 & 53 \\
\hline 7 & 4 & 32 & 28 \\
\hline 8 & 2 & 61 & 34 \\
\hline 9 & 0 & 6 & 2 \\
\hline
\end{tabular}

Table 6

Cumulative Hours of Technical Support and Pedagogical Guidance Provided to Faculty

Who Taught Online Courses During the Spring Semester of 2006

\begin{tabular}{|c|c|c|c|}
\hline Subject Number & $\begin{array}{c}\text { Online Courses } \\
\text { Taught (Prior to } \\
\text { Spring 2006) }\end{array}$ & $\begin{array}{c}\text { Cumulative Hours } \\
\text { of Technical } \\
\text { Support }\end{array}$ & $\begin{array}{c}\text { Cumulative Hours of } \\
\text { Pedagogical } \\
\text { Guidance }\end{array}$ \\
\hline 1 & 3 & 93 & 65 \\
\hline 2 & 4 & 93 & 122 \\
\hline 4 & 4 & 111 & 83 \\
\hline 5 & 2 & 15 & 42 \\
\hline 6 & 6 & 99 & 85 \\
\hline 6 & 6 & 113 & 87 \\
\hline 7 & 5 & 33 & 35 \\
\hline 8 & 3 & 73 & 37 \\
\hline 10 & 0 & 5 & 41 \\
\hline 11 & 5 & 54 & 36 \\
\hline 12 & 5 & 61 & 18 \\
\hline 13 & 0 & 27 & 9 \\
\hline 14 & 1 & 26 & 4 \\
\hline
\end{tabular}




\section{Students}

Students $(\mathrm{n}=519)$ in the 30 classes for which the instrument was administered were all pursuing either masters or doctoral level studies. The number of students who were taking courses for use in programs at other institutions and transferring credits from WVU is unknown, however, since HR\&E online courses have received little marketing or publicity it can be assumed that the vast majority of students considered WVU to be their home institution. As discussed in the methods section, the data for 20 students in three classes was excluded from the final analysis. Therefore, the final number of students in the survey was $n=499$.

\section{Quantitative Analysis of Data}

Two multiple regressions were conducted for the data collected. Findings are categorized by criterion variables.

\section{Regression Analyses for Instructional Design and Organization}

A multiple regression analysis was conducted in which the predictor variables technical support and pedagogical guidance provided to faculty were regressed on the criterion variable, student satisfaction with instructional design and organization. Number of online courses previously taught by faculty was also included as a predictor variable to test for possible covariance. Multiple regression, rather than a series of bivariate regressions, was used to protect against experiment-wise error $(\alpha=.05)$.

Prior to running the regression analysis, variables were examined for assumptions of multivariate analysis. Errors were assumed to follow a normal distribution, be independent and have a constant variance (homogeneity of variance). The assumptions of linearity, multicollinearity, and homogeneity of variance were met. 


\section{Tests of Linearity and Homogeneity}

A two step process was used to check for linearity and homogeneity of variance. In accordance with suggestions offered by Cohen, et al (2003), a scatterplot of standardized residuals versus predicted values was examined. Ideally no discernable pattern should emerge in the scatterplot. However, visual examination was inconclusive in this instance. This required a series of Levene's tests to be used to ensure that a significance of $\alpha<.05$ did not exist. The series of Levene's tests confirmed the assumptions of linearity and homogeneity of variance. The results are displayed in Table 7.

\section{Table 7}

Levene's t-tests on Two Predictors and One Co-Predictors by Instructional Design /

Organization

Variable $\quad t \quad d f \quad p$

Technical $\quad-2.473 \quad 474 \quad .168$

Support

$\begin{array}{llll}\text { Pedagogical } \quad .961 & 474 \quad .253\end{array}$

Guidance

$\begin{array}{llll}\text { Courses } & 1.032 & 474 & .404\end{array}$

Previously

Taught

Tests of Multicolinearity

Multicolinearity was addressed by obtaining tolerances and variance inflation factors. Examination of these values revealed that the predictor variables were not highly correlated with each other (Table 8). Tolerances are more than 0.10 and therefore are not viewed as indicators of extreme multicolinearity. VIF data are not in excess of 10 . The assumption of multicolinearity was met, maintaining the statistical integrity of the analysis. 
Multiple Regression Analysis

The regression model was statistically significant $\mathrm{F}(3,495)=4.990, s$, Sig. $=$ $.002 . \mathrm{R}^{2}$ indicated that $2.9 \%$ of the variance in the criterion variable (instructional design and organization) is explained by the predictors. The two predictors, technical support and pedagogical guidance were significant (Sig. $>.05, \rho<.05)$. The co-predictor, number of courses previously taught by faculty was not significant $($ Sig. $<.05, \rho>.05)$ (Table 8).

Table 8

Multiple Regression on Instructional Design / Organization Using Two Predictors and One Co-Predictor

$\begin{array}{lllllll}\text { Predictor } & B & S E B & \beta & t & \text { Sig. Tolerance VIF }\end{array}$

Variable

$\begin{array}{llllllll}\text { Technical } & -.027 & .009 & -.256 & -3.152 & .002 & .297 & 3.367\end{array}$

Support

$\begin{array}{llllllll}\text { Pedagogical } & .015 & .007 & .148 & 1.976 & .049 & .349 & 2.865\end{array}$

Guidance

$\begin{array}{llllllll}\text { Courses } & -.013 & .082 & -.008 & -.162 & .872 & .765 & 1.306\end{array}$

Previously

Taught

The findings indicate a negative relationship $(\beta=-.256)$ between hours of technical support provided to faculty and student satisfaction with instructional design and organization. The findings indicate a positive relationship $(\beta=.148)$ between hours of pedagogical guidance provided to faculty and student satisfaction with instructional design and organization.

\section{Regression Analyses for Facilitation of Discourse}

A multiple regression analysis was conducted in which the predictor variables technical support and pedagogical guidance provided to faculty were regressed on the criterion variable, student satisfaction with facilitation of discourse. Number of online 
courses previously taught by faculty was also included as a predictor variable to test for possible covariance. Multiple regression, rather than a series of bivariate regressions, was used to protect against experiment-wise error $(\alpha=.05)$.

Prior to running the regression analysis, variables were examined for assumptions of multivariate analysis. Errors were assumed to follow a normal distribution, be independent and have a constant variance (homogeneity of variance). The assumptions of linearity, multicolinearity, and homogeneity of variance were met.

\section{Tests of Linearity and Homogeneity}

A two step process was used to check for linearity and homogeneity of variance. In accordance with suggestions offered by Cohen, et al (2003), a scatterplot of standardized residuals versus predicted values was examined. Ideally no discernable pattern should emerge in the scatterplot. However, visual examination was inconclusive in this instance. This required a series of Levene's tests to be used to ensure that a significance of $\alpha<.05$ did not exist. The series of Levene's tests confirmed the assumptions of linearity and homogeneity of variance. The results are displayed in Table 9.

Table 9

Levene's t-tests on Two Predictors and One Co-Predictors by Facilitation of Discourse

Variable

Technical

Support

Pedagogical

Guidance

Courses

Previously

Taught

$\begin{array}{ccc}t & \mathrm{df} & p \\ -3.152 & 474 & .168 \\ 1.976 & 474 & .353 \\ -.162 & 474 & .148\end{array}$




\section{Tests of Multicolinearity}

Multicolinearity was addressed by obtaining tolerances and variance inflation factors. Examination of these values revealed that the predictor variables were not highly correlated with each other (Table 10). Tolerances are more than 0.10 and therefore are not viewed as indicators of extreme multicolinearity. VIF data are not in excess of 10. The assumption of multicolinearity was met, maintaining the statistical integrity of the analysis.

\section{Multiple Regression Analysis}

The regression model was statistically significant $\mathrm{F}(3,495)=3.075, \mathrm{~s}, \mathrm{Sig} .=$ $.049 . \mathrm{R}^{2}$ indicated that $1.8 \%$ of the variance in the criterion variable (facilitation of discourse) is explained by the predictors. The two predictors, technical support and pedagogical guidance were significant $($ Sig. $>.05, \rho<.05)$. The co-predictor, number of courses previously taught by faculty was not significant $($ Sig. $<.05, \rho>.05)$ (Table 10).

Table 10

Multiple Regression on Facilitation of Discourse Using Two Predictors and One Co-

Predictor

Predictor

Variable

Technical

$\begin{array}{llllll}B & S E & B & t & \text { Sig. Tolerance VIF }\end{array}$

$\begin{array}{llllllll}\text { Support } & -.023 & .009 & -.209 & -2.473 & .014 & .277 & 3.604\end{array}$

Pedagogical

Guidance

Courses

$\begin{array}{lllllll}.007 & .008 & .074 & .964 & .037 & .338 & 2.956\end{array}$

Previously

Taught

$\begin{array}{lllll}.092 & .089 & -.054 & 1.032 & .303\end{array}$

.715

The findings indicate a negative relationship $(\beta=-.209)$ between hours of technical support provided to faculty and student satisfaction with facilitation of 
discourse. The findings indicate a positive relationship $(\beta=.074)$ between hours of pedagogical guidance provided to faculty and student satisfaction with facilitation of discourse.

\section{Summary of Results}

Hours of technical support and pedagogical guidance provided to faculty were found to be significant predictor variables when regressed on student satisfaction with instructional design / organization at the $\alpha=.05$ level. The co-predictor, number of courses previously taught by faculty, was not a significant predictor at the $\alpha=.05$ level. Hours of technical support and pedagogical guidance provided to faculty accounted for $2.9 \%$ of the variability in student satisfaction with instructional design and organization. Hours of technical support and pedagogical guidance provided to faculty were found to be significant predictor variables when regressed against student satisfaction with facilitation of discourse at the $\alpha=.05$ level. The co-predictor, number of courses previously taught by faculty, was not significant predictor at the $\alpha=.05$ level. Hours of technical support and pedagogical guidance provided to faculty accounted for $1.8 \%$ of the variability in student satisfaction with facilitation of discourse. 


\section{CHAPTER 5}

\section{CONCLUSIONS, IMPLICATIONS, RECOMENDATIONS}

The purpose of this study was to explore the potential relationships between quantifiable faculty support mechanisms and student satisfaction in asynchronous learning environments. Based on a triangulation of case studies of best practice, two primary faculty support mechanisms, levels of technical support and pedagogical guidance were identified. These were used as predictor variables in this study. A copredictor, number of online courses previously taught by faculty, was also included in the study.

Student satisfaction was measured using two survey instruments that were very similar to ones developed by Shea, Swan, Li and Pickett (2005). The first survey instrument measured student satisfaction with instructional design / organization. The second survey instrument measured student satisfaction with facilitation of discourse. These were used as criterion variables in this study.

Multiple regression analysis was used to assess potential relationships between the predictor and criterion variables. The following sections address conclusions, implications and recommendations related to the multiple regression analyses and results presented in Chapter Four.

\section{Conclusions}

While previous research has revealed that technical support and pedagogical guidance are highly valued support structures by faculty teaching online courses, this study indicates that they are not necessarily factors that can be quantitatively correlated with student satisfaction using the procedures employed. Even though both of the 
regression analyses conducted in this study were found to be significant at the $\alpha=.05$ level, the predictor variables accounted for an extremely low percentage of the variability in student satisfaction.

Specifically, technical support and pedagogical guidance provided to faculty accounted for only $2.9 \%$ of the variability in student satisfaction with quantifiable levels of instructional design and organization. The same predictor variables accounted for an even lower, $1.8 \%$, of the variability in student satisfaction with facilitation of discourse.

While the regression line for both analyses was nearly flat it is interesting to note that the $\beta$ for technical support was negative in both instances. However, the values (-.256 when regressed against instructional design / organization and -.209 when regressed against facilitation of discourse) are so small that little can be inferred. Similarly, while positive, the $\beta$ for pedagogical guidance is so small (.148 when regressed against instructional design / organization and .074 when regressed against facilitation of discourse) that no meaningful conclusions can be inferred. The extremely low percentage of variability accounted for in this study indicates that factors other than the selected predictor variables are influencing student satisfaction.

The co-predictor, number of online courses previously taught by faculty, was found to not be significant. However, this finding is meaningful both in terms of overall implications of the study and future recommendations which are discussed below.

Implications

Implications related to this study takes two different forms: implications for practice and implications for theory. These two different categories are presented below. 


\section{Implications for Practice}

Currently, many faculty development programs, including the one at WVU's College of HR\&E, the site of this study, are based largely on hours of faculty support. This study demonstrates that this approach, while often responsible for producing high degrees of faculty satisfaction, should not be expected to necessarily produce high levels of student satisfaction.

I believe this finding is also reinforced by the non-significance of the copredictor, number of online courses previously taught by faculty. In many respects, the act of teaching a course is a type of training. Therefore, when repeated teaching experiences do not bring about higher student satisfaction it appears likely that other factors may be responsible.

With respect to the design of future training and support initiatives, factors other than hours of support need to be addressed. Dzuiban, Shea and Arbaugh (2005) suggest that as yet largely unexplored personal factors may be responsible for success in teaching online. This proposition is potentially reinforced by the findings of this study in which some instructors with relatively low quantities of technical support and pedagogical guidance were able to generate student satisfaction scores comparable to or better than instructors who received substantively greater levels of support in each of these areas.

An example of how instructor characteristics may influence student satisfaction can be found in research conducted at WVU's College of HR\&E on faculty perceptions of the use of technology in online courses. This work, in which I was involved, revealed a tendency among faculty with highly objectivist teaching orientations to confuse 
technological tools with applications of pedagogy in the online environment (Ice \& Phillips, 2006).

Other possible indicators, that I have observed in my support role at the College of HR\&E, include the ability of an instructor to project caring in the online environment and the ability to create a sense of community among students. Both of these items have been noted numerous times in the qualitative sections of the end of course surveys and in interviews for ongoing research projects. Though students note both of these themes frequently, much more research is needed to determine why students believe that a given instructor excels in these areas and what mechanisms underlie the ability to do so.

Themes similar to the previous two have also been noted by others in the field and are considered to be highly significant areas for further research (Ley, 2006). However, according to one of the leading researchers / practitioners in the field, Boria Sax, there is as of yet no clear consensus on the best mechanisms for conducting this type of research (personal communication, January 11, 2006).

\section{Implications for Theory}

In the introduction and literature review sections of this study, the Online Interaction Learning Model (OILM) was discussed in detail. The OILM, the prevailing theoretical model describing interactions within ALN, proposes that actions influencing any given moderator variable should create a measurable impact on any of the output variables; i.e., the five pillars of quality effectiveness (Benbunan-Fich, et al., 2005).

From a theoretical perspective, the cyclical feedback structure of the OILM suggests that a relationship should exist between: 1) Technical support provided to faculty and student satisfaction, and, 2) Pedagogical guidance provided to faculty and 
student satisfaction. As Harasim (1990) points out, in moderator-mediator-output models of conceptual change, contextual factors interact with each other to create change at all levels in a continuous feedback loop. As this is the basis for the OILM such dynamic changes to the moderator variables should produce change at the output level (BenbunanFich et al., 2005).

This study explored a call for research made by Bishop and SchWeber (2004) to develop a better understanding of the relationship between faculty and student satisfaction which is the purpose of this study. Specifically it focused on how technical support and pedagogical guidance, factors at the instructor-characteristics moderator level, are related to student satisfaction.

While the findings of this study indicate that a meaningful relationship does not exist between quantifiable support mechanisms that produce high levels of instructor satisfaction and student satisfaction it does not necessarily invalidate the OILM. The findings of this study suggest that future research into this set of mediator and output variables in the OILM should focus on other less quantifiable factors, such as personality traits; an issue discussed in the previous section.

\section{Recommendations}

Recommendations related to this study take two different forms: recommendations for practice and recommendations for research. These two different categories are presented below.

\section{Recommendations for Practice}

As discussed above, contemporary practices in training faculty to teach online are often based on an hours of contact approach. While such practices have been shown to 
produce high levels of faculty satisfaction at various institutions, including the site of this study, there appears to be no meaningful relationship between hours of technical support and pedagogical guidance provided to faculty and student satisfaction in online courses. Therefore, it may be necessary for those responsible for faculty training to rethink the effectiveness of an hours based approach when designing training and support programs.

However, determining the structure of training and support programs that produce both high levels of instructor and student satisfaction, in the most efficient manner, may be problematic. In a metastudy of best practices in online training, Wolf (2004) concluded that there is no consensus among leading practitioners as to what constitutes best practice in online faculty development. Further, her study concludes that the online teaching and learning environment is considered so different, by experts in the field, from traditional teaching that few if any face to face teacher training strategies would be of significant use in online faculty development programs.

As such, this study does not provide insight into proactive measures related to online faculty training, however, it does highlight a practice that is likely to be ineffective. Based on my interaction with faculty, it is my opinion that the needs of faculty are so varied that prescriptive training is often far inferior to individualized needs assessment and support.

For institutions, the ability to rapidly develop and deploy effective instructor training and support mechanisms should be considered critical. According to leading practitioners in the field, a second paradigm shift, one that will make education increasingly mobile by using increasingly compact technologies, is already impacting distance learning and is expected to become the delivery norm within three to five years. 
Therefore, in order for a given institution to remain competitive it will be necessary to have access to instructors who are already proficient in ALN based teaching and translate their skills to delivery via more compact technologies (Pferdehirt, Blanchard, Metcalf, Regan \& Smith, 2006).

Based on the findings of this study, I believe that WVU's College of HR\&E, as well as numerous other institutions, will be woefully unprepared to meet the challenges of training faculty to migrate towards increasingly complex delivery systems. While overall student satisfaction would be considered very good, among students completing surveys in this study, the results are likely unrelated to the structure of the training and support program; a program based largely on hours of contact time.

To become successful in promoting student satisfaction in ALN, I believe it is imperative that institutions begin to shift their focus from programs based on contact hours and explore how personal and pedagogical characteristics can be cultivated in faculty. This should be considered a top priority for institutions that are willing to recognize the general ineffectiveness of contact hours based training and support programs. Further directions for research in this area are explored in the following section.

\section{Recommendations for Further Research}

In this study no meaningful relationship was found to exist between quantifiable measures of technical support and pedagogical guidance provided to faculty and student satisfaction in online courses. However, as previously discussed, I do not believe that this finding invalidates the OILM. As noted in the implications for practice, implications for theory and recommendations for practice subsections, there exist suggestions in the 
literature that as yet unexplored personal factors may play an integral role in developing effective online praxis. I believe that future research should be focused in this direction.

The most effective way to further research in this area, in my opinion, would be to begin with highly qualitative case study analyses of factors that promote student satisfaction across a broad spectrum of courses. In this procedure, it is envisioned that students would be engaged in open ended dialogue regarding their experiences in online courses to unearth those elements most responsible for producing high degrees of satisfaction. From these, thematic similarities could be identified and specific acts or practices identified. Next, it should be possible to generate an instrument in which the themes detected in the series of case studies could be reduced to Likert scale items. A confirmatory factor analysis would then be conducted on the data from a relatively large $(\mathrm{n} \geq 1000)$ sample of students.

If such an analysis were to support the findings of a qualitative study, it would be desirable to assess how or if such practices could be taught. Perhaps, it might be the case that such practices are more closely related to personality traits, in which case no amount of training would likely be of benefit.

An example of this relates to the projection of caring and community building on the part of the instructor; topics I noted in the implications for practice subsection of this chapter. While many techniques exist for building community and enhancing ways to project ones character they might be of little value to an instructor who believes in a highly didactic mode of teaching. Similarly, if caring is found to be an important theme and an instructor has grown accustomed to not interacting with students, beyond the delivery of factual material, in the face to face environment it seems unlikely that they 
could be trained to display any higher levels of emotional contact in the online environment.

Another factor which, based on personal observations, I believe may be significant is the type of content the instructor chooses to utilize in ALN. Qualitative portions of student surveys have revealed that ALN learners may have a preference for content that requires higher order thinking and allows them to create more substantive interactions with the instructor and classmates. Clearly, the types of content that are utilized and the manner in which they are presented could impact student satisfaction with instructional design / organization. It is also an area which could be impacted by both technical support and pedagogical guidance provided to faculty.

Finally, qualitative data from student satisfaction surveys have revealed that assessment modes may impact student satisfaction. In many instances students have expressed the belief that a given type of assessment (i.e. multiple choice quizzes, essays, group projects, etc.) do not provide an appropriate means to demonstrate mastery of the knowledge that has been constructed in a given course. Interestingly, there has been no single preferred assessment strategy favored by a majority of students, nor is any method uniformly disliked. Though the data sets are too small to draw any significant conclusions from, there is a suggestion that students may favor assessments types that are related to the cognitive strategies that are employed in the study of content. If so, this appears to be a rich area for further research and is directly related to instructional design / organization.

Though these observations may give some guidance for further research it is unlikely that the study of any element in isolation will yield significant findings. Across 
the courses included in this study students have commented on specific weaknesses related to instructor apathy, feelings of isolation / lack of a sense of community, poor content selection or inappropriate assessment techniques. However, when the means for student satisfaction are compared there is very little difference between courses; as is reflected in the nearly flat regression lines. To me, this suggests that while an individual instructor or course may have weaknesses in one area they are likely offset by strengths in another. If so, this would indicate that instructor-related factors influencing student satisfaction interact in a complex fashion that may not be quantifiable. Teasing out these interactions through qualitative case study analysis will be exceedingly complex.

Despite these limitations, I believe such research is essential if we hope to achieve high levels of student satisfaction in ALN and build strong, effective learning communities. I have speculated, based on my experiences and knowledge of the literature, as to what I believe to be some of the most significant factors that merit further inquiry. However, many other factors and practices are likely to emerge as inquiry into this area progresses. What, I believe, this study demonstrates is that regardless of which faculty traits and practices are eventually identified as being significant in producing student satisfaction, they will not be factors that can be reduced to quantifiable applications. The act of helping students be successful and satisfied with the way they construct knowledge has been far from formulaic in the face to face classroom and, in my opinion, will remain so in the virtual classroom. 


\section{REFERENCES}

Alavi, M., \& Gallupe, R. (2003). Using information technology in learning: Case studies in business and management education programs. Academy of Management Learning and Education, 2(2), 139 - 153.

Alavi, M., \& Leidner, D. (2001). Research commentary: Technology mediated learning-A call for greater depth and breadth of research. Information Systems Research, $12(1), 1-10$.

Allen, I., \& Seaman, J. (2005). Growing by degrees: Online education in the United States, 2005. Needham, MA: SCOLE (Sloan Center for Online Education).

Allen, G., \& Thompson, A. (1995). Analysis of the effect of networking on computerassisted collaborative writing in a fifth grade classroom. Journal of Educational Computing Research, 12(1), 65-75.

Anderson, T., Rourke, L., Garrison, D., \& Archer, W. (2001). Assessing teaching presence in a computer conferencing context. Journal of Asynchronous Learning Networks 5 (2), 1-17.

Barron, R., \& Kenny, D. (1986). The moderator-mediator variable distinction in social psychological research : conceptual, strategic, and statistical considerations. Journal Of Personality and Social Psychology, 51(6), 1173 - 1182.

Benbunan-Fich, R., Hiltz, R., \& Harasim, L. (2005). The online interaction learning model: An integrated theoretical framework for learning networks. In S. Hiltz \& R. Goldman (Eds.), Learning together online: Research on asynchronous learning networks (pp. 19 - 37). Mahwah, NJ: Lawrence Erlbaum. 
Bender, T. (2003). Discussion-based online teaching to enhance student learning: Theory, practice and assessment. Sterling, VA: Stylus.

Bennett, S., \& Lockyer, L. (2004). Becoming an online teacher: Adapting to a changed environment for teaching and learning in higher education. Educational Media International, 41(3), 231-244.

Berliner, D. (1988, February). The development of expertise in pedagogy. Charles W. Hunt Memorial Lecture presented at the Annual Meeting of the American Association of Colleges for TEacher Education, New Orleans, LA.

Bernard, H. (2000). Social research methods: Qualitative and quantitative approaches. Thousand Oaks, CA: Sage.

Bishop, T., \& SchWeber, C. (2004). A systems approach to effective online teaching and learning: A preliminary examination of linkages between student and faculty satisfaction. In J. C. Moore (Ed.), Elements of quality online education: Into the mainstream: Wisdom from the Sloan Consortium (pp. 65 - 77). Needham, MA: SCOLE (Sloan Center for Online Education).

Botsch, C., \& Botsch, R. (2000, July/August). Gaining Faculty Acceptance for Online Courses at a Traditional College. The Technology Source - Michigan Virtual University, article 1. Retrieved March 30, 2005, from http://ts.mivu.org/default.asp?show=article \&id $=788$

Brown, D. (Ed.). (2003). Developing faculty to use technology: Programs and strategies to enhance teaching. Bolton, MA: Anker.

Chickering, A., \& Gamson, Z. (1987). Seven principles for good practice in undergraduate education. AAHE Bulletin, March 1987, 3-7. 
Cohen, J., Cohen, P., West, S., \& Aiken, L. (2003). Applied multiple

regression/correlation analysis for the behavioral sciences, $3^{\text {rd }}$ edition. Mahwah, NJ: Lawrence Erlbaum.

Collis, B., \& Nijhuis, G. (2000). The instructor as manager: Time and task. The internet and higher education, 3, 75-97.

Cook, K., \& Grant-Davie, K. (Eds.). 2005. Online education: Global questions, local answers. Amityville, NY: Baywood.

Coppola, N. (2005). Changing roles for online teachers of technical communication. In K. Cook \& K. Grant-Davie (Eds.), Online education: Global Questions, local answers (pp. 89-100). Amityville, NY: Baywood.

Coppola, N., Hiltz, S., \& Rotter, N. (2002). Becoming a virtual professor: Pedagogical roles and asynchronous learning networks. Journal of Management Information Systems. 18(4), 169-189.

DiPaolo, A. (2001, August). The rise of a new educational industry: Lessons learned in the evolution of online learning. Keynote speech at the Distance Learning 2001 Conference, Madison, Wisconsin.

Dziuban, C., Shea, P., \& Arbaugh, J. (2005). Faculty roles and satisfaction in asynchronous learning networks. In S. Hiltz \& R. Goldman (Eds.), Learning together online: Research on asynchronous learning networks (pp. 19 - 37). Mahwah, NJ: Lawrence Erlbaum.

Epper, R., \& Bates, A. (Eds.). (2001). Teaching faculty how to use technology: Best practices from leading institutions. Westport, CT: Oryx. 
Etzioni, A. (1964). Modern organizations. Englewood Cliffs, NJ: Prentice-Hall.

Ferrazzi, G. (July / August, 2003). Ambitious Vision, Limited Resources: A Flexible Approach to Distributed Learning. The Technology Source - Michigan Virtual University. Retrieved March 30, 2005, from http://ts.mivu.org/default.asp?show=article\&id=946

Fredrickson, E., Pickett, A., Shea, P., Pelz, W., \& Swan, K. (2000). Factors influencing faculty satisfaction with asynchronous teaching and learning in the SUNY learning network. Journal of Asynchronous Learning Networks, 4(3), 245 - 278.

Freire, P. (2004). Pedagogy of the oppressed. (M. Ramos, Trans.) New York: Continuum International. (Original work published 1970)

Gold, S. (2001). A constructivist approach to online training for online teachers. Journal of Asynchronous Learning Networks, 5(1), 36 - 57.

Green, Thomas. (1971). The activities of teaching. New York: McGraw-Hill.

Harrisim, L. (Ed.). (1990). On-line education: Perspectives on a new medium. New York: Praeger Greenwood.

Hartman, J., Dzuiban, C., \& Moskal, P. (2000). Faculty satisfaction in ALNs: A dependent or independent variable? Journal of Asynchronous Learning Networks, $4(3), 155-179$.

Hawkins, B. (2005, November). Asynchronous challenge: Moving from pedagogy to cyberagogy. Presentation at the 11th Sloan-C International Conference on Asynchronous Learning Networks, Orlando, FL. 
Hiltz, S. (1996). Post-course questionnaire for students - Virtual University project.

Retrieved November 17, 2004, from

http://www.alnresearch.org/JSP/Resources/instrument_full text.jsp?index $=120 \&$ $\underline{\text { \&article } \mathrm{id}=6 \&}$

Hiltz, S. (1988). Productivity enhancement from computer-mediated communication: a systems contingency approach. Communications of the ACM_31(12),1438-1454.

Hiltz, S., \& Shea, P. (2005). The student in the online classroom. In S. Hiltz \& R.

Goldman (Eds.), Learning together online: Research on asynchronous learning networks (pp. 145-168). Mahwah, NJ: Lawrence Erlbaum.

Hiltz, S., \& Wellman, B. (1997). Asynchronous learning networks as a virtual classroom. Communications of the ACM, 40(9), 44-49.

Hock, D. (1999). Birth of the chaordic age. San Francisco: Berrett-Koehler.

Ice, P. \& Phillips, P. (2006). Perceptions of pedagogy being a function of technology: An observed phenomenon in online faculty with objectivist teaching and learning orientations. Article in submission.

Joyce, B., Weil, M., \& Calhoun, E. (2004). Models of Teaching, $7^{\text {th }}$ Edition. New York: Pearson.

Kaminski, K., \& Milheim, W. (2002, November/December). Institutional challenges in the creation and delivery of an online degree program. The Technology SourceMichigan Virtual University. Retrieved March 30, 2005, from http://ts.mivu.org/default.asp?show $=$ article\&id=929 
Ley, K. (2006, August). Virtually being there: Establishing social presence. Presentation at the $22^{\text {nd }}$ Annual Conference on Distance Teaching and Learning, Madison, WI. Lynch, Maggie McVay. (2001, November/December). Effective Student Preparation for Online Learning. The Technology Source - Michigan Virtual University, article 5. Retrieved March 30, 2005, from http://ts.mivu.org/default.asp?show=article\&id $=901$

McKeachie, W. (Ed.) (1986). Teaching and learning in the college classroom: A review of the research literature. Ann Arbor, MI: University of Michigan.

Mayadas, F., Bourne, J., \& Moore, J. (2002) Introduction. In J. Bourne \& J. Moore (Eds.). Elements of quality of online education: Practice and direction, volume 4 in the Sloan-C series (pp. 7-11). Needham, MA: SCOLE (Sloan Center for Online Education).

Maeroff, G. (2003). A classroom of one. NY: Palgrave Macmillan.

Mertens, D. (2005). Research and evaluation in education and psychology: Integrating diversity with quantitative, qualitative and mixed methods, $2^{\text {nd }}$ edition. Thousand Oaks, CA: Sage.

Monolescu, D., Schifter, C. \& Greenwood, L. (2003). The Distance Education Evolution: Issues and Case Studies. Hershey, PA: Information Science Publishing. Moore, A. (2001). Designing advanced learning communities: Virginia Tech's story. In R. Epper \& A. Bates (Eds.), Teaching faculty how to use technology: Best practices from leading institutions. (pp. 79-92). Westport, CT: Onyx.

Moore, J. (2002). Elements of quality: The Sloan-C framework. Needham, MA: SCOLE (Sloan Center for Online Education). 
Morrison, G., Ross, S., \& Kemp, J. (2004). Designing Effective Instruction, $4^{\text {th }}$ Edition. Hoboken, NJ: Wiley/Jossey-Bass.

National Center for Education Statistics. (2003). 2001, Condition of education:

Participation in adult learning. Retrieved September 9, 2005 from http://nces.ed.gov/programs/coe/2003/section1/indicator08.asp

Patton, M. (2002). Qualitative research and educational methods, $3^{\text {rd }}$ edition. Thousand Oaks, CA: Sage.

Pferdehirt, W., Blanchard, J., Metcalf, D., Regan, B., \& Smith, T. (2006, August). New directions in delivering distance education using mobile communication devices. Presentation at the $22^{\text {nd }}$ Annual Conference on Distance Teaching and Learning, Madison, WI.

Reath, Jason. (2001). A Case Study in Creating a University-Wide Program to Increase Fluency in Information Technology. WebCT. Retrieved September 12, 2005 from http://www.webct.com/service/ViewContent?contentID $=4236608$

Royal, T. (2005, November). Teaching traditional faculty to develop online courses and teach online. Presentation at the 11th Sloan-C International Conference on Asynchronous Learning Networks, Orlando, FL.

Salmon, G. (2002). E-tivities. New York: Falmer.

Schwartz, E., \& Phillips, S. (2005). Supporting faculty in the use of technology. In D. Brown (Ed.), Developing faculty to use technology: Programs and strategies to enhance teaching (pp. 103-107). Bolton, MA: Anker. 
Shea, P., Swan, K., Li, C., \& Pickett, A. (2005). Developing learning community in online asynchronous college courses: The role of teaching presence. Journal of Asynchronous Learning Networks, 9(4), 59-82.

Shea, P., Swan, K., Fredrickson, E., \& Pickett, A. (2002). Student satisfaction and reported learning in the SUNY Learning Network. In J. Bourne \& J. Moore (Eds.), Quality online education, vol. 3. (pp. 145-155). Needham, MA: SCOLE (Sloan Center for Online Education).

Spencer, D. (2000). Survey of distance learning students experiences. Retrieved November 17, 2004, from http://www.alnresearch.org/JSP/Resources/instrument_full text.jsp?index $=135 \& \&$ $\underline{\text { article } \mathrm{id}=7 \&}$

Thompson, M. (2004). Faculty self-study research project: Examining the online workload. Journal of Asynchronous Learning Networks, 8(3), 84-88.

Thompson, M. (2000). World Campus course outcomes survey: Spring 2000. Retrieved November 17, 2004, from http://www.alnresearch.org/JSP/Resources/instrument full text.jsp?index $=150 \& \&$ $\underline{\text { article } \mathrm{id}=4 \&}$

Willis, L.\& Lockee, B. (2004). A pragmatic instructional design model for distance learning. International Journal of Instructional Media. 31(1), 9 - 17.

Wolf, Patricia. (2004). Best practices in the training of faculty to teach online. Unpublished doctoral dissertation, University of Maryland University College, Adelphi, MD. 
Yin, R. (1998). Case study research: Design and methods. Applied Social Research Methods, Vol. 5. Thousand Oaks, CA: Sage.

Zotti, R. (2005, November). Strategies for successful growth of online learning programs. Presentation at the 11th Sloan-C International Conference on Asynchronous Learning Networks, Orlando, FL. 
Appendix A.

Student Satisfaction Survey

1. 1-1 Course Goals

Course goals were clear to me.

1. Strongly Agree

2. Agree

3. Neutral

4. Disagree

5. Strongly Disagree

Save Answer

\section{1-2 Requirements}

Work requirements and grading system were clear from the begining.

1. Strongly Agree

2. Agree

3. Neutral

4. Disagree

5. Strongly Disagree

Save Answer 


\section{1-3 Navigation}

The course was easy to navigate.

1. Strongly Agree

2. Agree

3. Neutral

4. Disagree

5. Strongly Disagree

Save Answer

4. 1-4 Presentation

Course content was presented in a logical and easy to follow order.

1. Strongly Agree

2. Agree

3. Neutral

4. Disagree

5. Strongly Disagree

Save Answer 


\section{1-5 Content Quality}

Quality of digital content was good.

1. Strongly Agree

2. Agree

3. Neutral

4. Disagree

5. Strongly Disagree

Save Answer

\section{1-6 User Friendliness}

Overall the course was set up in a user friendly manner.

\section{Strongly Agree}

2. Agree

3. Neutral

4. Disagree

5. Strongly Disagree

Save Answer 
'. 1-7 Effieiency

Overall the course management system increased the efficiency of my education.

1. Strongly Agree

2. Agree

3. Neutral

4. Disagree

5. Strongly Disagree

Save Answer

1. 1-8 Quality of Experience

Overall the course management system increased the quality of my educational experience.

1. Strongly Agree

2. Agree

3. Neutral

4. Disagree

5. Strongly Disagree

Save Answer

9. 1-9 Course Comments

Please provide any additional comments related to course effectiveness or structure.

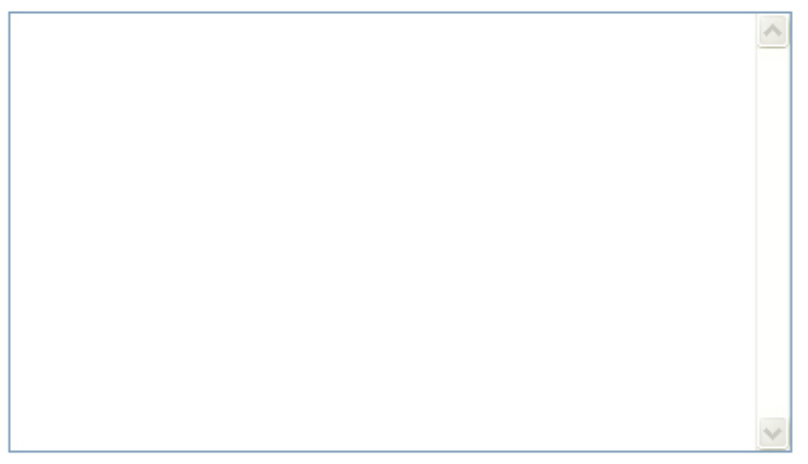

Save Answer 
10. 2-1 Instructor / Subject Matter

Through course design and activities the instructor demonstrated a mastery of the subject matter.
1. Strongly Agree
2. Agree
3. Neutral
4. Disagree
5. Strongly Disagree
Save Answer

11. 2-2 Instructor / Preparation

The instructor's preparation of course content was effective.

1. Strongly Agree

2. Agree

3. Neutral

4. Disagree

5. Strongly Disagree

Save Answer 


\section{2-3 Instructor / Intent}

The instructor was able to convey their intent online.

1. Strongly Agree

2. Agree

3. Neutral

4. Disagree

5. Strongly Disagree

\section{Save Answer}

\section{2-4 Instructor / Feedback}

The instructor's feedback and other responses were timely.

1. Strongly Agree

2. Agree

3. Neutral

4. Disagree

5. Strongly Disagree

Save Answer 
14. 2-5 Instructor / Student Participation

Through the course design and interaction the instructor encourages students to participate.

1. Strongly Agree

2. Agree

3. Neutral

4. Disagree

5. Strongly Disagree

Save Answer

15. 2-6 Instructor / Learning Community

Through the course design and interaction the instructor helped students build an effective learning community.

1. Strongly Agree

2. Agree

3. Neutral

4. Disagree

5. Strongly Disagree

Save Answer 
16. 2-7 Instructor / Overall

Overall the instructor was effective in presenting materials and facilitating learning activities.
1. Strongly Agree
2. Agree
3. Neutral
4. Disagree
5. Strongly Disagree

\section{Save Answer}

17. 2-8 Instructor / Recomendation

I would recomend this instructor to other students.

1. Strongly Agree

2. Agree

3. Neutral

4. Disagree

5. Strongly Disagree

Save Answer

\section{2-9 Instructor Comments}

Please provide any additional comments related to the course instructor.

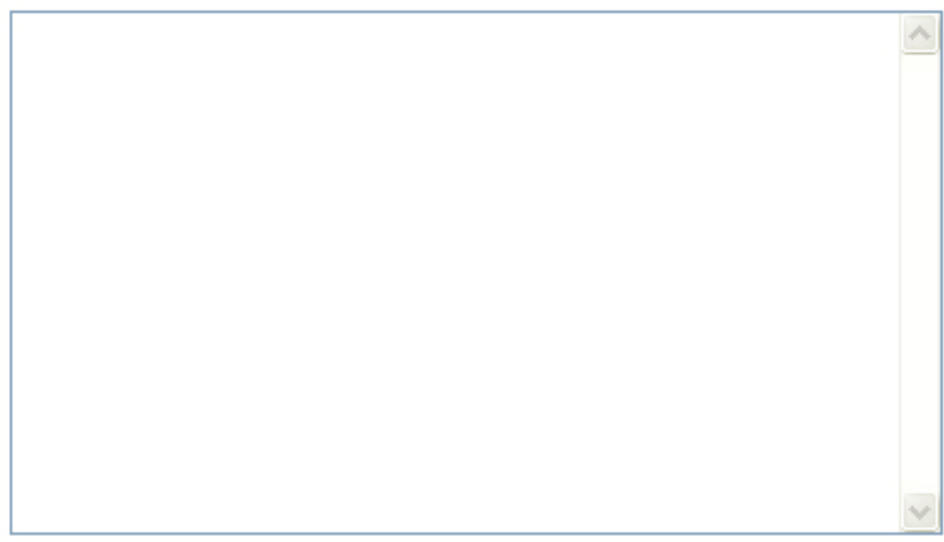




\section{3-1 Interest}

I became more interested in the subject.

1. Strongly Agree

2. Agree

3. Neutral

4. Disagree

5. Strongly Disagree

Save Answer

\section{3-2 Factual Learning}

I learned a great deal of factual material.

1. Strongly Agree

2. Agree

3. Neutral

4. Disagree

5. Strongly Disagree

Save Answer 


\section{3-3 Conceptual Learning}

I gained a good understanding of concepts in the content area.

1. Strongly Agree

2. Agree

3. Neutral

4. Disagree

5. Strongly Disagree

Save Answer

22. 3-4 Ability to Communicate

I developed the ability to communicate clearly about this subject.

1. Strongly Agree

2. Agree

3. Neutral

4. Disagree

5. Strongly Disagree

Save Answer 
23. 3-5 Critical Thinking

My ability to critically assess facts and concepts in the content area increased.

1. Strongly Agree

2. Agree

3. Neutral

4. Disagree

5. Strongly Disagree

Save Answer

\section{3-6 Theory and Practice}

My ability to integrate theory and practice in the content area increased.

1. Strongly Agree

2. Agree

3. Neutral

4. Disagree

5. Strongly Disagree

Save Answer 


\section{3-7 Inquiry}

I was stimulated to initiate additional inquiry.

1. Strongly Agree

2. Agree

3. Neutral

4. Disagree

5. Strongly Disagree

\section{Save Answer}

\section{3-8 Participation}

I participated actively in class discussion.

1. Strongly Agree

2. Agree

3. Neutral

4. Disagree

5. Strongly Disagree

Save Answer 


\section{3-9 Learning}

The assignments aided my learning.

1. Strongly Agree

2. Agree

3. Neutral

4. Disagree

5. Strongly Disagree

Save Answer

28. 3-10 Confidence

I became more confident in expressing my ideas about the content area.

1. Strongly Agree

2. Agree

3. Neutral

4. Disagree

5. Strongly Disagree

Save Answer 


\section{3-11 Reflectivity}

The course format allowed me to develop meaningful, reflective postings.
1. Strongly Agree
2. Agree
3. Neutral
4. Disagree
5. Strongly Disagree
Save Answer

30. 3-12 Reflectivity

I was encouraged to think for myself.

1. Strongly Agree

2. Agree

3. Neutral

4. Disagree

5. Strongly Disagree

Save Answer 


\section{3-13 Perception of Others}

I learned to value others points of view related to the content area.
1. Strongly Agree

2. Agree

3. Neutral

4. Disagree

5. Strongly Disagree

Save Answer

32. 3-14 Motivation

I was motivated to do my best work.

1. Strongly Agree

2. Agree

3. Neutral

4. Disagree

5. Strongly Disagree

Save Answer 


\section{3-15 Learning Community}

I became and active participant in a learning community.

1. Strongly Agree

2. Agree

3. Neutral

4. Disagree

5. Strongly Disagree

Save Answer

34. 3-16 Perceptions of Effectiveness

Please provide any additional comments related your perceptions of course strengths and weaknesses.

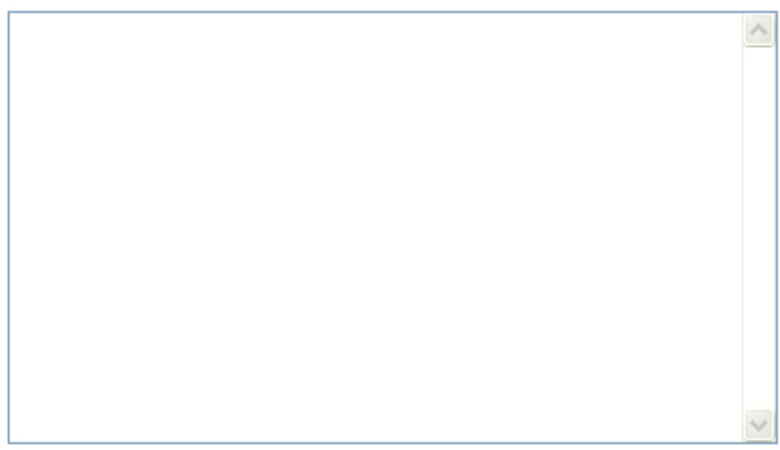

Save Answer 
35. 4-1 Online / Convenience

Taking this course online was more convenient than if I would have taken it in a traditional setting.

1. Strongly Agree

2. Agree

3. Neutral

4. Disagree

5. Strongly Disagree

Save Answer

36. 4-2 Online / Inhibition

I flet more inhibited in this course than if I would havein the traditional setting.

1. Strongly Agree

2. Agree

3. Neutral

4. Disagree

5. Strongly Disagree

Save Answer 
37. 4-3 Online / Effort

I didn't have to work as hard in this course as I do in traditional courses.

1. Strongly Agree

2. Agree

3. Neutral

4. Disagree

5. Strongly Disagree

Save Answer

38. 4-4 Online / Communication - Students

I communicated more with other students than I would have in a traditional course.

1. Strongly Agree

2. Agree

3. Neutral

4. Disagree

5. Strongly Disagree

Save Answer 
39. 4-5 Online / Communication - Instructor

I communicated more with the instructor than I would have in a traditional course.

1. Strongly Agree

2. Agree

3. Neutral

4. Disagree

5. Strongly Disagree

Save Answer

40. 4-6 Online / Product Quality

The fact that my assignments would be read by other students increased my motivation to do a thorough job.

1. Strongly Agree

2. Agree

3. Neutral

4. Disagree

5. Strongly Disagree

Save Answer 
41. 4-7 Online / Interest

The course was more boring than a traditional class.

1. Strongly Agree

2. Agree

3. Neutral

4. Disagree

5. Strongly Disagree

Save Answer

42. 4-8 Online / Involvement

I felt more involved in the course than I would have in a traditional class.

1. Strongly Agree

2. Agree

3. Neutral

4. Disagree

5. Strongly Disagree

Save Answer 
43. 4-9 Online / Comments from Others

I found reading comments made by other students to be useful.

1. Strongly Agree

2. Agree

3. Neutral

4. Disagree

5. Strongly Disagree

Save Answer

44. 4-10 Online / Learning from Others

I found that reading the work generated by other students increased my knowledge of the content area.

1. Strongly Agree

2. Agree

3. Neutral

4. Disagree

5. Strongly Disagree

Save Answer 
45. 4-11 Online / Future Courses

Based on my experience in this course I would choose NOT to take another online course.

1. Strongly Agree

2. Agree

3. Neutral

4. Disagree

5. Strongly Disagree

Save Answer

46. 4-12 Online / Comparison

I found this course to be a better learning experience than normal face-to-face courses.

1. Strongly Agree

2. Agree

3. Neutral

4. Disagree

5. Strongly Disagree

Save Answer 
47. 4-13 Online / Overall

Overall I was satisfied with my experiences in this course.

1. Strongly Agree

2. Agree

3. Neutral

4. Disagree

5. Strongly Disagree

Save Answer

48. 4-14 Online Effectiveness

Please provide any additional comments related your perceptions of online line learning in this course.

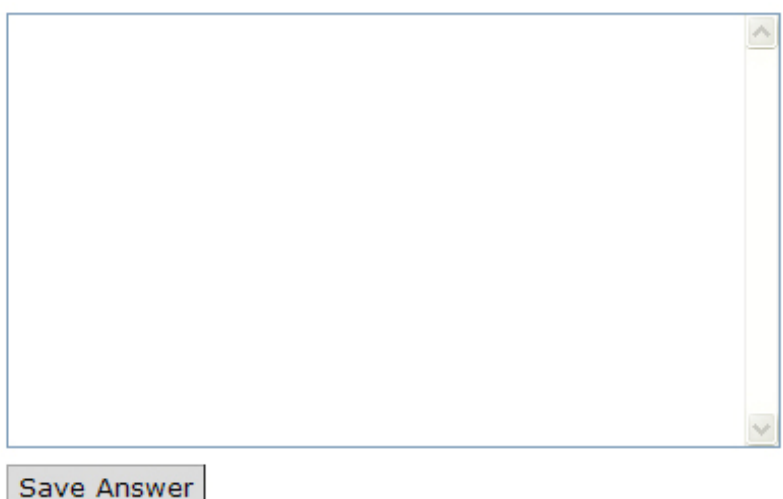


Appendix B.

Instructional Design and Organization Subscale

1. 1-1 Course Goals

Course goals were clear to me.

1. Strongly Agree

2. Agree

3. Neutral

4. Disagree

5. Strongly Disagree

Save Answer

\section{1-2 Requirements}

Work requirements and grading system were clear from the begining.

1. Strongly Agree

2. Agree

3. Neutral

4. Disagree

5. Strongly Disagree

Save Answer 


\section{1-3 Navigation}

The course was easy to navigate.

1. Strongly Agree

2. Agree

3. Neutral

4. Disagree

5. Strongly Disagree

Save Answer

4. 1-4 Presentation

Course content was presented in a logical and easy to follow order.

1. Strongly Agree

2. Agree

3. Neutral

4. Disagree

5. Strongly Disagree

Save Answer 


\section{1-6 User Friendliness}

Overall the course was set up in a user friendly manner.
1. Strongly Agree
2. Agree
3. Neutral
4. Disagree
5. Strongly Disagree

\section{Save Answer}

11. 2-2 Instructor / Preparation

The instructor's preparation of course content was effective.

1. Strongly Agree

2. Agree

3. Neutral

4. Disagree

5. Strongly Disagree

Save Answer 


\section{Appendix C.}

\section{Facilitation of Discourse Subscale}

14. 2-5 Instructor / Student Participation

Through the course design and interaction the instructor encourages students to participate.
1. Strongly Agree
2. Agree
3. Neutral
4. Disagree
5. Strongly Disagree

Save Answer

15. 2-6 Instructor / Learning Community

Through the course design and interaction the instructor helped students build an effective learning community.
1. Strongly Agree
2. Agree
3. Neutral
4. Disagree
5. Strongly Disagree 
16. 2-7 Instructor / Overall

Overall the instructor was effective in presenting materials and facilitating learning activities.

1. Strongly Agree

2. Agree

3. Neutral

4. Disagree

5. Strongly Disagree

Save Answer

\section{3-10 Confidence}

I became more confident in expressing my ideas about the content area.

1. Strongly Agree

2. Agree

3. Neutral

4. Disagree

5. Strongly Disagree

Save Answer 


\section{3-11 Reflectivity}

The course format allowed me to develop meaningful, reflective postings.
1. Strongly Agree
2. Agree
3. Neutral
4. Disagree
5. Strongly Disagree
Save Answer

33. 3-15 Learning Community

I became and active participant in a learning community.
1. Strongly Agree
2. Agree
3. Neutral
4. Disagree
5. Strongly Disagree

Save Answer 